\title{
THE INFLUENCE OF NATURAL AND SYNTHETIC LIGANDS ON THE TRANSPORT AND FUNCTION OF METAL IONS IN THE ENVIRONMENT
}

\author{
Arthur E. Martell \\ Department of Chemistry, Texas $A \& M$ University, College Station, \\ Texas 77843, USA
}

\begin{abstract}
The environmental effects of coordination compounds are discussed from the point of view of the introduction of unnatural levels of metal ions and ligands into various parts of the ecosystem. The transport of toxic metals, with special reference to mercury, lead, and cadmium, is described, and the available information on the nature of these metals as they exist in the environment is examined. Consideration is given to the occurrence, constitution and properties of natural ligands in the environment.

As a guide to the introduction of excessive ligands into the environment, the properties and uses of the ligands now in large scale commercial production are examined. Applications of EDTA, NTA, and sodium tripolyphosphate, all of which are used in large amounts, are considered in detail. An analysis of the current controversy over the substitution of NTA for tripolyphosphate in detergents indicates that NTA should be favoured for this large scale application and that the environmental impact of NTA should be minimal.
\end{abstract}

\section{INTRODUCTION}

For the purposes of this paper environmental effects of coordination compounds are considered to be disturbances of the natural levels of metal ions and metal complexes in the ecosystem, which consists of plant and animal life as well as air, water, soil and sediments. There are two general routes by which man has disturbed this natural balance: (1) by the introduction of abnormal amounts of metal salts and metal complexes into one or more parts of the system; (2) by the introduction of synthetic ligands or abnormal levels of natural ligands, into the environment. Both types of pollution have had serious consequences. Toxic levels of some metals seriously affect human health and the health of other forms of animal life. The introduction of large amounts of ligands into the environment has raised questions among the public concerning their toxic effects, and concerning their possible influence on levels of both beneficial and toxic metal compounds.

It is the purpose of this paper to look into the various ways that recent and present activities on the part of industry and the consumer have affected metal and ligand levels. Examples of both types of pollution will be examined, and areas where more information is needed will be pointed out. Some 
attention will be given to governmental and public policy, and to the dangers of drawing conclusions with insufficient data at hand.

\section{(A) ENVIRONMENTAL POLLUTION BY THE INTRODUCTION OF METAL SALTS AND COMPLEXES}

From the point of view of environmental pollution, metal ions can be classified as toxic and accessible, toxic but inaccessible (either very rare or in very insoluble forms), and relatively non-toxic. A list of metals classified in this manner ${ }^{1}$ is given in Table 1.

Table 1. Toxicities of metals

\begin{tabular}{ccccccc}
\hline \multicolumn{2}{c}{ Toxic and Accessible } & \multicolumn{2}{c}{ Toxic but not Accessible } & \multicolumn{2}{c}{ Non-Toxic } \\
\hline $\mathrm{Be}$ & $\mathrm{As}$ & $\mathrm{Ag}$ & $\mathrm{Ti}$ & $\mathrm{Ga}$ & $\mathrm{Li}$ & $\mathrm{Ca}$ \\
$\mathrm{Co}$ & $\mathrm{Sb}$ & $\mathbf{H g}$ & $\mathrm{Hf}$ & $\mathrm{La}$ & $\mathrm{Na}$ & $\mathrm{Sr}$ \\
$\mathrm{Ni}$ & $\mathrm{Bi}$ & $\mathrm{Au}$ & $\mathrm{Zr}$ & $\mathrm{Os}$ & $\mathrm{K}$ & $\mathrm{Al}$ \\
$\mathrm{Cu}$ & $\mathrm{Se}$ & $\mathrm{Pd}$ & $\mathrm{W}$ & $\mathrm{Rh}$ & $\mathrm{Rb}$ & $\mathrm{Fe}$ \\
$\mathrm{Zn}$ & $\mathrm{Te}$ & $\mathrm{Pt}$ & $\mathrm{Nb}$ & $\mathrm{Ir}$ & $\mathrm{Mg}$ & $\mathrm{Si}$ \\
$\mathrm{Cd}$ & $\mathrm{Sn}$ & & $\mathrm{Ta}$ & $\mathrm{Ru}$ & & \\
& $\mathrm{Pb}$ & \multicolumn{7}{c}{ Lanthanides } & $\mathrm{Ba}$ & & \\
& & \multicolumn{2}{c}{$\mathrm{Re}$} \\
\hline
\end{tabular}

Toxic metals move through the environment through the so-called 'geocycle', illustrated in Figure 1. When the free or complexed forms of these metals find their way into fresh and marine waters, including water in the soil, they may find their way into plants, microorganisms, animals, fish, and eventually man. Man's activities may result in the introduction of considerable amounts of certain toxic metals at the points indicated in the geocycle. Pollution by such metals can have considerable effect on all living organisms in its path, and may find its way back to man at toxic levels. Bacterial action may strongly influence the form in which these metals exist in water, soils, and sediments, and may also provide complexing ligands to act as soluble carriers for these metal ions.

\section{Essential trace metals}

Many of the metals listed in Table 1 as toxic are actually essential for life or for maintaining health of animals and man at much lower (trace) levels. Because the required levels are frequently very low, and much lower than the levels at which they occur in foods, many trace metal requirements have not been demonstrated until recently. Table 2 presents a periodic arrangement of the major and minor elements now known to be required for maintaining life and animal health. Additional elements now under investigation $^{2}$ as possibly required are also indicated. It is interesting to note that about half of the natural elements are now considered to have an essential function in living systems.

The trace metals now known to be essential are listed in Table 3, in chronological order of the dates that the requirement was demonstrated ${ }^{3}$. 


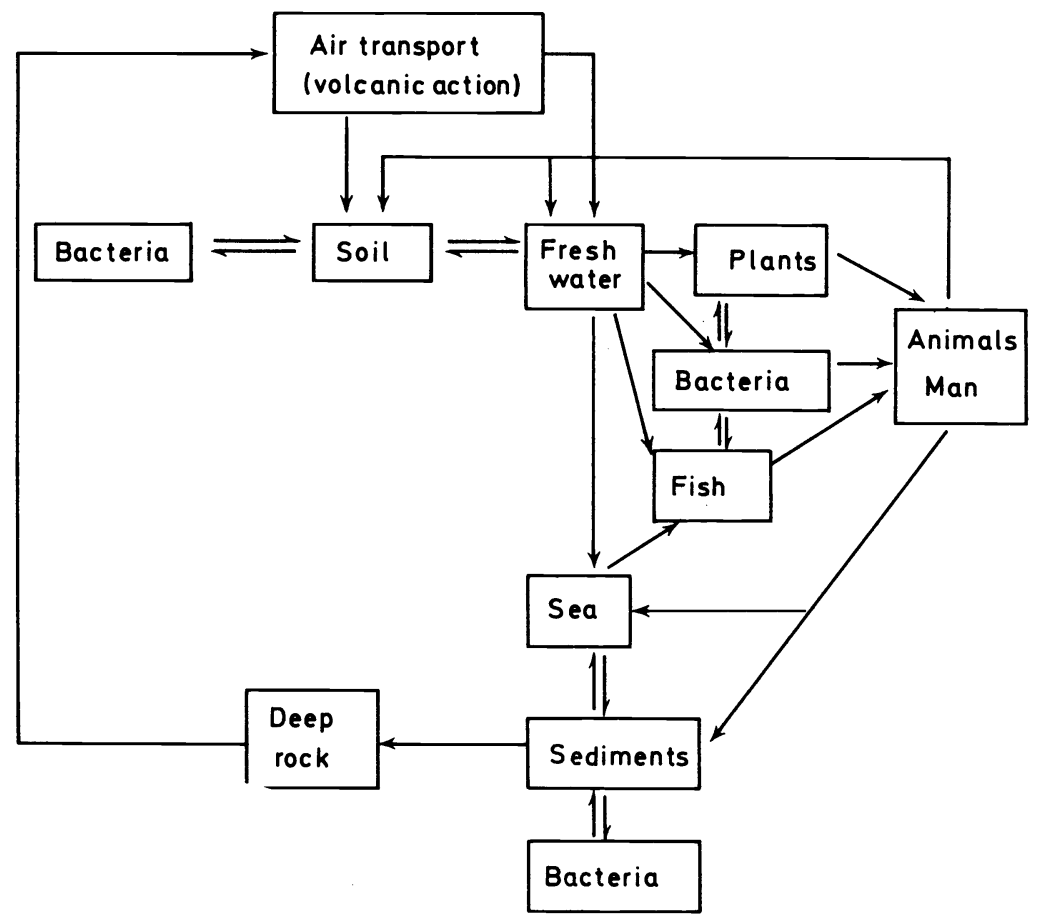

Figure 1. Movement of metals through the geocycle.

Since all such metals are toxic when taken in abnormally large amounts, the toxic as well as the beneficial effects are listed.

While it has been established that many trace metals are required for life and animal health, the concentrations of these metals as they occur in food and in many environmental sources such as airborne dust are usually orders of magnitude higher than the very low levels necessary for deficiency effects to appear. As an example 4 . of the presence of trace metals in dust, Table 4 presents an analysis of dust found on laboratory and domestic furnace filters. The abnormally large amounts of lead will be discussed below.

While it is obvious that interest in the presence and nature of minor elements is of importance from the points of view of low level requirements and the occasional existence of toxic levels in the environment, there are other reasons for concern about the concentration levels of these essential elements. Of considerable interest is the possibility of chronic diseases associated with the uptake of more typical levels of metals from water, air, and food ${ }^{5}$. Recent reports have shown statistical correlations between metal content of drinking water and the incidence of cardiovascular disease ${ }^{6,7}$. In many of these studies water hardness and the presence of minor elements have been shown to correlate inversely with cardiovascular mortality rates ${ }^{8}$. Statistically significant negative correlations have been found between atherosclerotic heart disease and the levels of lithium and vanadium in municipal water ${ }^{9}$. It has also been shown that there are statistically significant 
ARTHUR E. MARTELL

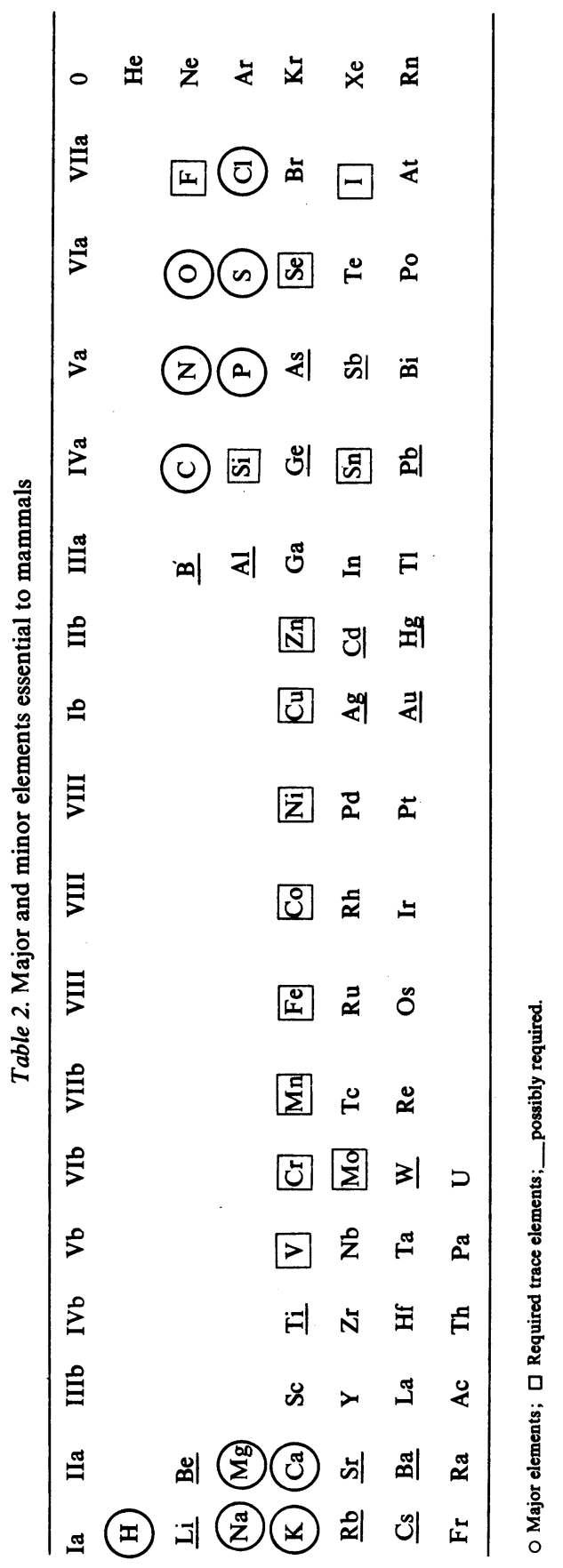


METAL IONS AND LIGANDS IN THE ENVIRONMENT

Table 3. Effects of deficiency and excess of essential trace metals ${ }^{3}$

\begin{tabular}{|c|c|c|c|}
\hline Metal & $\begin{array}{l}\text { Discovery } \\
\text { date }\end{array}$ & Deficiency symptom or function & Toxic effects \\
\hline $\mathbf{F e}$ & $\begin{array}{l}17 \text { th } \\
\text { century }\end{array}$ & anaemia & haemochromatosis \\
\hline $\mathrm{Cu}$ & 1928 & $\begin{array}{l}\text { anaemia, rupture of blood vessels, } \\
\text { bone defects }\end{array}$ & $\begin{array}{l}\text { Wilson's disease, injury to nerves, } \\
\text { liver, kidney and capillaries }\end{array}$ \\
\hline Mn & 1931 & $\begin{array}{l}\text { impaired growth, skeletal } \\
\text { abnุormalities, ataxia of newborn }\end{array}$ & $\begin{array}{l}\text { symptoms similar to Parkinson's } \\
\text { syndrome (nerve damage) }\end{array}$ \\
\hline $\mathrm{Zn}$ & 1934 & $\begin{array}{l}\text { impaired growth, taste, sexual } \\
\text { development, required for } \\
\text { vitamin A }\end{array}$ & *general poisoning symptoms \\
\hline Co & 1935 & $\begin{array}{l}\text { anaemia in livestock, required for } \\
\text { vitamin } B_{12}\end{array}$ & polycythaemia \\
\hline Mo & 1953 & required for enzyme function & teart in cattle \\
\hline $\mathrm{Se}$ & 1957 & $\begin{array}{l}\text { liver necrosis, reduced glucose } \\
\text { tolerance, increased susceptibility } \\
\text { to } \mathrm{Cd} \text { and } \mathrm{Hg}\end{array}$ & $\begin{array}{l}\text { alkali disease and blind staggers } \\
\text { in livestock }\end{array}$ \\
\hline $\mathrm{Cr}$ & 1959 & $\begin{array}{l}\text { glucose tolerance adversely } \\
\text { affected }\end{array}$ & ${ }^{*}$ general poisoning symptoms \\
\hline Sn & 1970 & poor growth, defective teeth & *general poisoning symptoms \\
\hline $\mathbf{N i}$ & 1970 & adverse effects in leg and chickens & *general poisoning symptoms \\
\hline v & 1971 & $\begin{array}{l}\text { depression of growth rate and } \\
\text { lipid oxidation }\end{array}$ & *general poisoning symptoms \\
\hline $\mathbf{S i}$ & 1972 & $\begin{array}{l}\text { influences growth and structure of } \\
\text { connective tissue }\end{array}$ & urinary calculi in some cases \\
\hline $\mathbf{P b}$ & 1973 & influences growth & $\begin{array}{l}\text { lassitude, vomiting, loss of appetite, } \\
\text { convulsions, brain damage, im- } \\
\text { paired kidney and liver function }\end{array}$ \\
\hline
\end{tabular}

* Abdominal pain, weakness, nausea, vomiting, purging, haemorrhage, convulsions, coma.

correlations between mortality from different types of cancer and concentrations of several trace elements, including arsenic, beryllium, cadmium, lead and nickel, in water supplies.

Such epidemiological studies indicate the importance of understanding the nature of metals in the environment, the factors that control metal

Table 4. Trace elements composition of dust from laboratory and domestic furnace filters ${ }^{4}$

\begin{tabular}{|c|c|c|c|c|c|}
\hline \multirow[b]{2}{*}{ Element } & \multicolumn{2}{|c|}{ p.p.m. in dust } & \multirow[b]{2}{*}{ Element } & \multicolumn{2}{|c|}{ p.p.m. in dust } \\
\hline & Furnace filter & Laboratory filter & & Furnace filter & Laboratory filter \\
\hline $\mathrm{Ag}$ & 5 & - & Mn & 160 & 140 \\
\hline $\mathrm{Ca}$ & 10000 & 70 & $\mathrm{Ni}$ & 160 & 89 \\
\hline Co & 19 & - & $\mathrm{Pb}$ & 7400 & 14620 \\
\hline $\mathrm{Cu}$ & 82 & 38 & Sn & 66 & 110 \\
\hline $\mathrm{Fe}$ & 5300 & 140 & $\mathbf{S r}$ & 86 & Trace \\
\hline K & 3 & - & V & 70 & 20 \\
\hline $\mathbf{M g}$ & 8200 & 720 & $\mathrm{Zn}$ & 900 & - \\
\hline
\end{tabular}

(Al, B, Cr, Na, Si and Ti were already present in the filter material and could not be detected as constituents of dust alone.) 
ARTHUR E. MARTELL

levels and transport, and the routes that metals may take through food chains to animals and man. While these correlations of metal levels with disease cannot be taken as an indication of direct cause and effect relationships, they certainly indicate the need for detailed study and research in this general area.

\section{Nature of trace metals in the environment}

The generally low concentrations of minor elements in fresh and marine water systems indicate that inorganic complexes are largely dissociated and that the dissolved metals may exist primarily in the ionic state. It should be remembered, however, that large fractions of the total metal content will be adsorbed on particulate matter, and considerable amounts may occur in colloidal forms such as hydrous oxides and other finely-dispersed insoluble materials. As an example of the situation generally encountered, Table 5 presents the distribution of metals between particulate and 'dissolved' forms as a function of filter pore size. It is evident that a large fraction of readily-hydrolysed metals must exist as suspended solid material, whereas the more basic metals are primarily in solution form. This behaviour greatly complicates any attempts to carry out equilibrium treatment of metal ions and complexes in natural waters. Quite generally natural waters are not in a state of equilibrium, and such elements as $\mathrm{Fe}, \mathrm{Al}, \mathrm{Mn}$ and $\mathrm{Ti}$, that form insoluble hydroxides, are frequently found at much higher levels than equilibrium treatments based on solubility would predict. Coprecipitation is another process that disturbs the equilibria of metal ions in natural systems. Naturally forming precipitates such as calcium carbonate can bring down large fractions of the soluble trace metals present.

Table 5. Concentrations of metals in a typical fresh-water stream as a function of filter pore size

\begin{tabular}{lrrr} 
& & \multicolumn{2}{c}{ Filter pore size } \\
\cline { 3 - 4 } Metal & Unfiltered & $0.45 \mu \mathrm{m}$ & $0.1 \mu \mathrm{m}$ \\
\hline $\mathrm{Al}$ & 310 & 77 & 57 \\
$\mathrm{Ba}$ & 90 & 87 & 80 \\
$\mathrm{~B}$ & 31 & 16 & 17 \\
$\mathrm{Cu}$ & 2 & 1 & 2 \\
$\mathrm{Fe}$ & 740 & 240 & 49 \\
$\mathrm{Mn}$ & 200 & 170 & 160 \\
$\mathrm{Ni}$ & 8 & 6 & $<5$ \\
$\mathrm{Sr}$ & 67 & 73 & 70 \\
$\mathrm{Ti}$ & 7 & 2 & $>2$ \\
\hline
\end{tabular}

\section{Natural organic ligands}

Naturally occurring organic compounds such as humic and fulvic acids, carbohydrates and proteinaceous material play an important role in controlling the solubilities and activities of metals in natural waters. In Table 6, which shows the average composition data of the major constituents of the sea $^{10}$, it is seen that the major ligands available are halide, carbonate, 
Table 6. Major metal ions and ligands in the sea

\begin{tabular}{clll}
\hline Meatal ion & Molarity & Ligands & Molarity \\
\hline $\mathrm{Na}^{+}$ & 0.47 & $\mathrm{Cl}^{-}$ & 0.55 \\
$\mathrm{Mg}^{2+}$ & 0.054 & $\mathrm{SO}_{4}^{2-}$ & 0.028 \\
$\mathrm{Ca}^{2+}$ & 0.010 & $\mathrm{HCO}_{3}^{-}$ & 0.0023 \\
$\mathrm{~K}^{+}$ & 0.010 & $\mathrm{Br}^{-}$ & 0.00083 \\
$\mathrm{Sr}^{2+}$ & 0.00015 & $\mathrm{~F}^{-}$ & 0.00007 \\
& & $\left(\mathrm{H}_{3} \mathrm{BO}_{3}\right)$ & 0.00043 \\
& & Organic & $10^{-4}-10^{-5}$ \\
& & compounds & \\
\hline
\end{tabular}

and sulphate, all of which are considerably dissociated, as noted above. Although present in relatively low concentrations, organic ligands may be one of the controlling factors in metal transport, in absorption on suspended and bottom sediments, and in their uptake by biota ${ }^{11}$. Many trace organics derived from the degradation of plant and animal tissues have functional groups that can form chelates of metals, thus imparting some stability even in dilute solution. The donor groups in humic and fulvic acids ${ }^{12,13}$ indicated below are recognized as among those that form quite stable complexes, especially when they act in a concerted fashion to produce chelate rings.

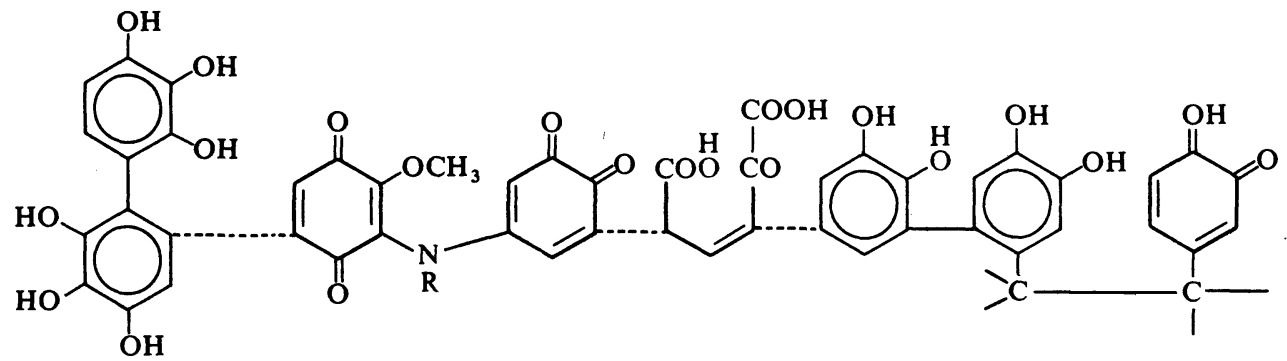

Schematic representation of donor groups in humic acids ${ }^{12}$.<smiles></smiles><smiles>C=C(C(=O)O[W])C(=O)O[W]</smiles>

Types of coordination ascribed to fulvic acids ${ }^{13}$.

Humic acid is a macromolecular material of variable composition consisting of a core unit plus hydrolysed protein and carbohydrate fractions. The core has a highly condensed partially aromatic carbon structure, and contains functional groups derived from lignin and resorcinol phenolic moieties. These include carboxyl, hydroxyl, phenolic, carbonyl and methoxy groups as indicated above. Although there are procedures for isolating and purifying humic acids reproducibly from a given source, detailed research 
on humic acid complexes is complicated by lack of information of the structure of the macroligand, and the fact that its composition varies with both the geographic location and the type of system from which it is obtained.

Fulvic acid is a macromolecular weight acid and alkali-soluble degradation product of humic acids containing carboxyl, phenolic and aliphatic hydroxyl groups. Although its structure is unknown, procedures have been developed for the preparation of reasonably reproducible samples and formation constants for its simple metal complexes ${ }^{14,15}$ and for its mixed ligand complexes ${ }^{13}$ have been reported. Because of the variable nature of the sources and the conditions under which it is formed, fulvic acids in nature vary widely in metal ion affinity and the applicability of purified samples to the real world can be only a rough approximation.

\section{Interactions with organisms}

Because of the large quantities of zooplankton and phytoplankton, and their large surface to volume ratios, it is believed that such organisms are a major factor in the transport of trace metals in the oceans and in fresh water systems. Such transport can occur through ingestion into the organism with food material but may also occur by ion exchange and adsorption on tissue or membrane surfaces. Complexation seems to be an important process in biological uptake of metals, which generally increases with increasing tendency of the metal toward complex formation. Thus alkaline earth metals are found to concentrate considerably less than the transition metals $\mathrm{Cu}, \mathrm{Ni}, \mathrm{Co}, \mathrm{Zn}$ and $\mathrm{Mn}$. Concentration factors as great as 200000 have been observed (in this case, with lead) for tropical oceanic zooplankton.

It is apparent from the above that the factors influencing trace metal levels and transport are complex and vary widely from place to place. Obviously the factors involved are not well understood, nor are they readily measurable. Much work needs to be done before the behaviour of an environmental system can be predicted on the basis of its content and the movement of metals and ligands in and out of the system. Perhaps the best way to arrive at an understanding of the present state of knowledge in this field is to look at the work done with those metals that have received the most attention: mercury, lead, and cadmium. The behaviour of these metals in the environment will be considered below.

\section{Mercury}

Mercury pollution on an extensive scale probably dates from the introduction of methylmercury salts for seed preservation in Germany in 1914. By the time that its toxic effects were recognized in Sweden and banned in 1966, farmers in the USA were using 40 times more alkylmercury compounds per acre than were Swedish farmers. Although there were many fatalities throughout the world resulting from agricultural applications, concern about mercury pollution did not develop in the USA until it was realized that industrial pollution of lakes and streams had resulted in contamination of fish above tolerable levels of 0.5-1.0 part per million.

Table 7 lists the various ways in which mercury is utilized in the USA. The chief source of contamination of lakes and streams is commercial chloralkali production with mercury cells. This becomes apparent if it is remem- 
METAL IONS AND LIGANDS IN THE ENVIRONMENT

Table 7. Consumption of mercury in the USA in $1969^{a}$

\begin{tabular}{lclc}
\hline \multicolumn{1}{c}{ Source } & Pounds $\times 10^{-5}$ & \multicolumn{1}{c}{ Source } & Pounds $\times 10^{-5}$ \\
\hline Chlor-alkali production & 16 & Agriculture & 2.0 \\
Electrical equipment & 14 & Laboratory use & 1.5 \\
Paints & 7.4 & Pharmaceuticals & 0.6 \\
Instruments & 5.3 & Pulp and paper manufacture & 0.4 \\
Dental applications & 2.3 & Miscellaneous & 7.4 \\
Catalysts & 2.3 & Total & 59 \\
\hline
\end{tabular}

"Data from US Bureau of Mines, as reported by Schubert ${ }^{10}$.

bered that the figure given for chlor-alkali production represents primarily the amount used for replacement of the mercury lost to the environment. Since 1970, awareness of the problem has resulted in control measures that have reduced chlor-alkali contamination by an order of magnitude. However,' after many years of continuous contamination, river and lake sediments have high levels of mercury that do not seem to change appreciably with time. Thus mercury contamination, and its effect on aquatic life, will be with us for many decades.

The distribution and transport of mercury is somewhat unique because of the special properties of the metal and its compounds: volatility, tendency to form stable alkyl derivatives, and the disproportionation reaction $\mathrm{Hg}_{2}^{2+} \rightleftharpoons \mathrm{Hg}^{2+}+\mathrm{Hg}^{\circ}$. The interconversions of these three forms of mercury can be catalysed by microorganisms. The insoluble mineral $\mathrm{HgS}$ can be oxidized to $\mathrm{HgSO}_{4}$ by aerobic bacteria. Also released in sediments or in water, it may then be reduced to elemental mercury by a number of bacteria or by reducing ligands such as humic acid. The reduction to $\mathrm{Hg}^{\circ}$ by bacteria may be considered detoxification since the mercury may then be dispersed through the atmosphere by volatilization. An alternative bacterial detoxification mechanism is the conversion of $\mathrm{Hg}^{2+}$ to $\mathrm{CH}_{3} \mathrm{Hg}^{+}$and $\left(\mathrm{CH}_{3}\right)_{2} \mathrm{Hg}$. It has been pointed out by Wood ${ }^{17}$ that these methylation reactions are carried out by enzymes containing methylcorrinoids as co-factors, according to the following reaction. Recent reports ${ }^{18,19}$ have described formation of both $\mathrm{CH}_{3} \mathrm{Hg}^{+}$and $\left(\mathrm{CH}_{3}\right)_{2} \mathrm{Hg}$ from such methyl-vitamin $\mathrm{B}_{12}$ derivatives.

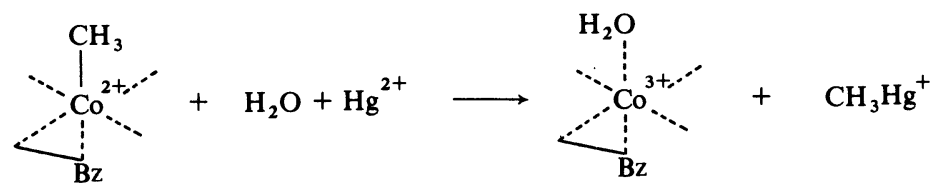

Since dimethylmercury is volatile, ultimate methylation of the type indicated above results in loss of the mercury to the atmosphere. Once in the atmosphere, the dimethylmercury is photolysed by ultra-violet light to give $\mathrm{Hg}^{\circ}$, methane and ethane.

The biological cycle for mercury is outlined in Figure 2. There are microorganisms in the sediments and in water that can convert both dimethylmercury and methylmercury to less toxic $\mathrm{Hg}^{\circ}$, which, however, is still toxic to mammals and man. It is well known that transport of mercury to man 


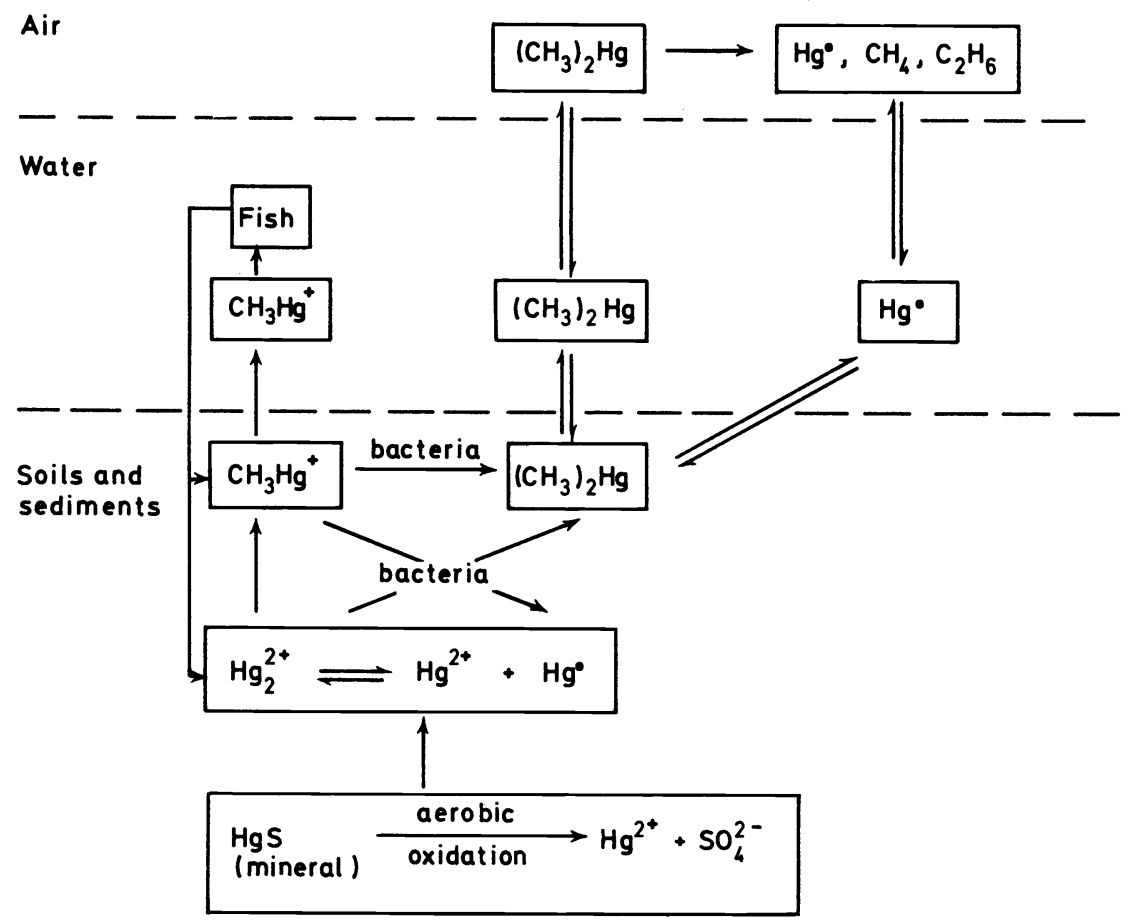

Figure 2. Biological chemical cycle for mercury.

can occur by absorption of the extremely toxic methylmercury, $\mathrm{CH}_{3} \mathrm{Hg}^{+}$, by fish, which are then consumed as food.

Under natural conditions the various forms of mercury shown in Figure 2 may be absent or present in very small amounts, whereas in some areas with access to mineral mercury deposits or areas subjected to dumping of mercury wastes by industry, the amounts can be appreciable. For example it has been found that the concentrations of mercury in lake sediments near industrial mercury-type electrolytic chlor-alkali cells can amount to as much as 3-4 parts per million, or even much higher, depending on the proximity to plant effluent. Electrolytic mercury cells emit mercury in vapour form as well as in colloidal form in aqueous solutions dumped into nearby streams or lakes. Because of the dynamic aspects of the cycle shown in Figure 2, it is apparent that fish will become contaminated with methylmercury in such regions. The amounts picked up can be far in excess of the legal limit of one half part per million set for foods by the EPA (Environmental Protection Agency).

Public and government concern about fish contamination has resulted in the prohibition of commercial fishing in areas of mercury contamination. It has also resulted in more careful control of electrolytic mercury cells to prevent the considerable loss of mercury that had resulted from careless plant operation. The safety measures that have been instituted by the chlor- 
alkali producers in the USA has greatly lowered the contamination rate from this source.

On the basis of chemical and physical properties it is possible to predict which metals can be transformed in the manner indicated above for mercury. For example it is possible to conclude that tin, palladium, platinum, gold and thallium will be methylated in the environment, but that lead, cadmium and zinc, which do not form stable alkyl-metal ions in aqueous solution, will not be methylated. These predictions have been demonstrated experimentally to be correct ${ }^{20}$.

\section{Lead}

Lead pollution may be more widespread and more serious than that of any other metal at the present time. As indicated in Table 8, more than 98 per cent of the 400 million pounds of lead released to the atmosphere in the USA each year comes from the combustion of gasoline ${ }^{21,22}$. About half of the particulate lead emissions from automobiles is deposited close

Table 8. Lead emission in the USA in 1968

\begin{tabular}{lrlr}
\hline \multicolumn{1}{c}{ Source } & Tons Pb/year & \multicolumn{1}{c}{ Source } & Tons Pb/year \\
\hline Gasoline combustion & 181000 & Brass manufacture & 521 \\
Coal combustion & 920 & Lead oxide manufacture & 20 \\
Fuel oil combustion & 24 & Gasoline transfer & 36 \\
Lead alkyl manufacture & 810 & Total & 184316 \\
Lead smelting & 985 & & \\
\hline
\end{tabular}

to highways, while the remainder is dispersed in the atmosphere as an aerosol with a mean residence time of 7-30 days, depending on rainfall and atmospheric conditions. The highest incidence of lead in dust and soils is found in urban areas. Municipal dust may contain up to 5 p.p.m. of lead, while surface soils in urban areas may contain from one to two orders of magnitude higher concentrations. Lead in soils near highways is concentrated at the surface, and can reach levels of 1000 p.p.m. adjacent to the highways, decreasing rapidly with distance from the highway. The abnormally high levels of lead found on a laboratory filter, as indicated by the data in Table 4, is without doubt due to contamination of air by automobile engine exhaust, since the laboratory is located in Long Beach, California, an urban area having considerable pollution from gasoline fumes. An interesting indication of worldwide lead pollution is the increase in the lead content of Greenland snow from a baseline 25 years ago to about 400 times normal levels at the present time.

As indicated in Figure 3, adapted from reference 20, the distribution of lead in the environment led to the conclusion that movement is mainly through the atmosphere in the form of insoluble particulate matter. Very little of the lead is present in water in soluble form, and the bulk of the lead is retained in soil and sediments. Under the present conditions airborne lead varies by three orders of magnitude $\left(0.01\right.$ to $\left.10 \mu \mathrm{g} / \mathrm{m}^{3}\right)$ depending on location, but generally seems to have reached a steady state in most areas. 


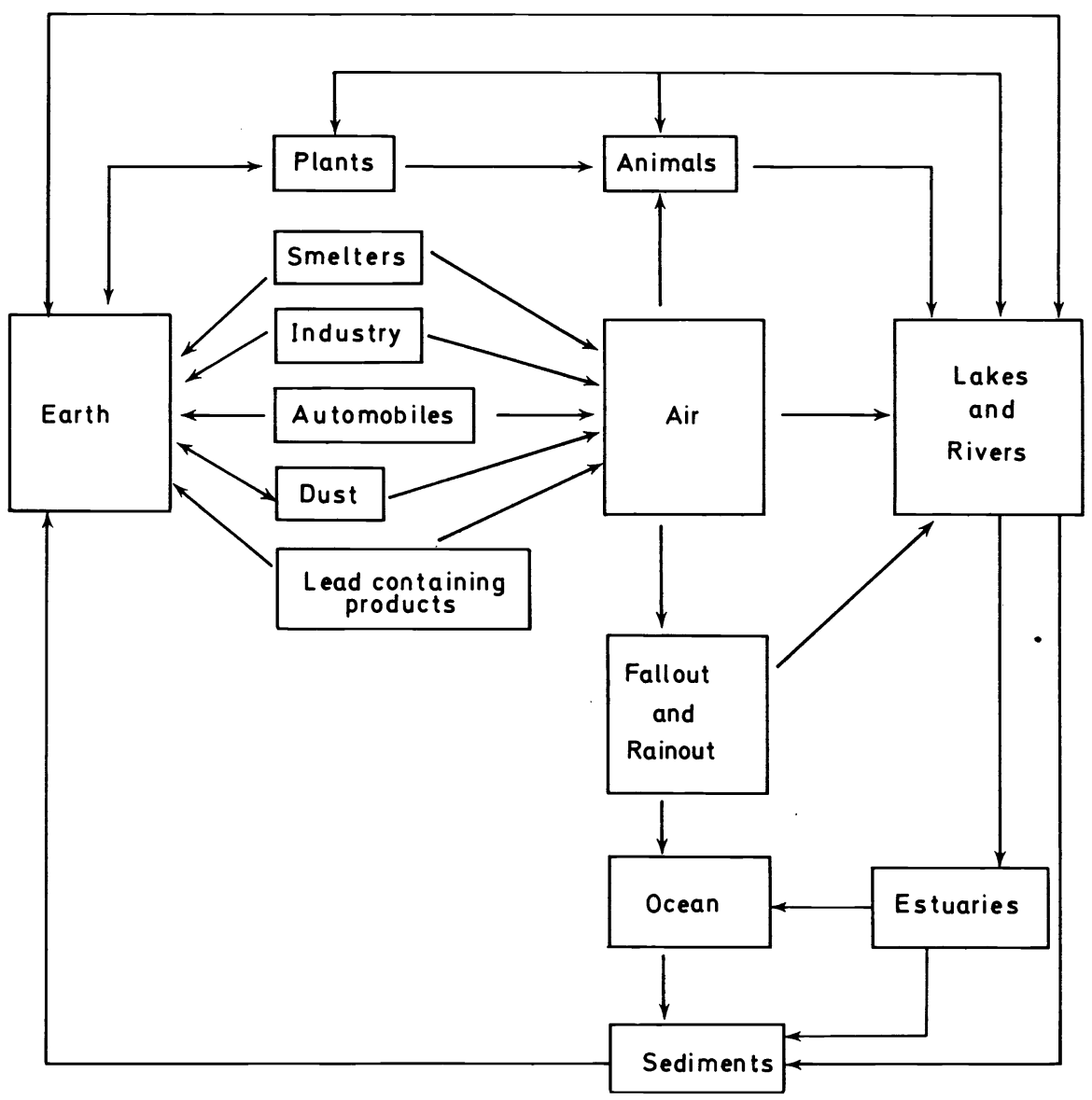

Figure 3. Flow chart showing possible cycling pathways and compartments for lead in the ecosystem.

Lead content of surface soils and sediments has been increasing slowly and is expected to increase further during the next decade.

Transport of lead by living organisms is not very well understood. Very little soil lead seems to be taken up by plants but rainfall seems to provide a route in some cases. Transfer from food plants to animals does not tend to transfer to other animals, or to recycle to plants, since lead in animals is mainly concentrated in bone and is thus removed from the food chain. There seems to be little information available on transport of lead in the oceans. Also, the role of microorganisms in the biotransfer of lead is generally unknown, as are the factors that influence transfer rates between compartments in the ecosystem. Thus it is seen that very little is known about the pathways and compartments suggested in Figure 3.

\section{Lead in man}

The main source of lead in man is through the food chain. There seems 
to be no direct evidence for absorption through the lungs, the particulate matter apparently residing in the lung tissues along with other dust constituents for long periods of time. Approximately 95 per cent of the lead in the body is stored in bone, and is generally inert. The small mobile fraction in soft tissues is associated with the acute toxic effects of lead, and is usually measured on the basis of the blood lead content. Blood levels and spontaneous renal excretion of lead have been used as a measure of recent exposure, since bone deposition takes place slowly. However, blood and urine levels vary considerably and unpredictably and do not provide a reliable indication of body burden or hazard potential. Of special interest is a new diagnostic technique derived from the therapeutic use of EDTA and other chelating agents for the removal of labile lead from the body. Thus the degree of recent exposure to lead is measured by the increased urinary excretion of the lead-EDTA complex following the injection of $\mathrm{Na}_{2} \mathrm{CaEDTA}$. Excretion of more than $1.0 \mathrm{mg}$ of lead during the first $24 \mathrm{~h}$ has been taken as an indication of dangerous exposure. The assumption is that the mobilization of lead in this way is directly related to the toxic fraction of the lead that is present in soft tissues and in labile bone surface. This method has been employed to indicate lead poisoning in workers in lead industries ${ }^{23}$, and in children ${ }^{24}$. Similar results have been obtained with oral administration of penicillamine ${ }^{25}$.

Although it is not the purpose of this paper to go into clinical details of heavy metal poisoning, something should be stated about the difference between acute and chronic lead poisoning. Low continuous absorption results in asymptomatic chronic poisoning in which blood and soft tissue levels are non-critical and steady deposition in the bone takes place. Acute lead poisoning, exhibiting the progressive symptoms listed in Table 3, results from an appreciable increase in the exposure levels producing chronic poisoning, from exposure to a sudden large dose, or to the little-understood occasional disturbances that mobilize the inert bone lead into the soft tissues and the blood stream. The principal victims of lead poisoning are industrial workers who come into contact with appreciable amounts of lead, and children in urban areas that ingest considerable non-food items such as lead-based paint and materials laden with dust of high lead content.

\section{Cadmium}

It has been estimated that about $5 \times 10^{6}$ pounds of cadmium are released each year in the USA into the air, water and soils ${ }^{26}$. Most of the sources of cadmium pollution are industrial and the greatest contamination is therefore found in urban areas where metallurgical plants, cadmium plating companies, and battery fabricators are located. Aside from the problems and amounts associated with lead from automobile exhaust, the routes of industrial release and transport of cadmium seem to be similar to those of lead. Here also, there is little information available on transport between different compartments of the ecosystem. Little is known about the role of microorganisms in the biotransfer and biotransformation of cadmium.

At birth the body contains no cadmium. Through five per cent absorption of ingested cadmium, the levels gradually build up to a total body burden of $10-20 \mathrm{mg}$ of cadmium. Smoking seems to provide a much greater source of 
cadmium than oral ingestion with the levels in smokers generally reaching more than twice those of non-smokers. Acute symptoms resulting from the ingestion of as little as $15 \mathrm{mg}$ of cadmium salts involve nausea and vomiting. Chronic exposure can lead to emphysema.

\section{(B) UNNATURAL LIGANDS IN THE ENVIRONMENT}

When complexing ligands are introduced into the environment through the dumping of waste chemicals, or through the effluent of municipal sewage plants, the question immediately arises of the effects of these ligands on the metal ions that they happen to encounter. Some serious concerns have been expressed that sequestering agents (ligands forming soluble complexes) could labilize and cause the migration of toxic metals otherwise present in sediments or soils in an insoluble and relatively harmless form. For example, could EDTA or NTA, when released in rivers and lakes, cause the solubilization and migration of mercury or lead compounds deposited in the sediments? If this happened, there would be danger of absorption of toxic metals by fish and of entry of the metal into municipal water supplies.

One way to determine which synthetic ligands, and how much, are released to the envirionment is to take a look at the applications of those complexing agents that are manufactured in large quantities. The largest class of complexing agents being manufactured and used in our modern economy is the group of water-soluble ligands known as sequestering agents, named on the basis of their property of usually forming stable, water-soluble complexes of a wide variety of metal ions. Let us examine the available data on sequestering agents now in general use, consider the nature of the applications of these materials and estimate possible environmental and health hazards.

\section{Sequestering agents of commercial interest}

As can be seen from the examples listed in Plate I, most commercially available sequestering agents at present are aminocarboxylic acids, and all of these compounds may be considered to be either EDTA, NTA, or analogues of their basic structures in which some of the functional groups are varied while others remain the same. The aminocarboxylates such as NTA and EDTA have the properties of complexing a wide variety of metal ions and hence have application where general metal ion complexation is needed. NTA has an advantage because of its low cost, while EDTA, which costs about three times NTA on a per weight basis, has the advantage of higher stabilities of its metal complexes and greater efficacy at lower concentrations of metal ion and ligand.

Derivatives of NTA and EDTA listed in Plate I contain functional groups that improve their properties for specific metal ions or for special reaction conditions. Thus DTPA complexes are generally more stable than those of EDTA, and the ligand is especially useful for metal ions of high coordination number that tend to precipitate (at higher $\mathrm{pH}$ ) in the presence of EDTA. Similarly, those analogues of NTA and EDTA containing hydroxyethyl groups keep the ferric ion in solution at higher pII values than do the parent compounds. Thus the series of ligands NTA, HIDA (hydroxyethyliminodiacetic acid), DHG (dihydroxyethylglycine) and TEA (triethanol- 
METAL IONS AND LIGANDS IN THE ENVIRONMENT

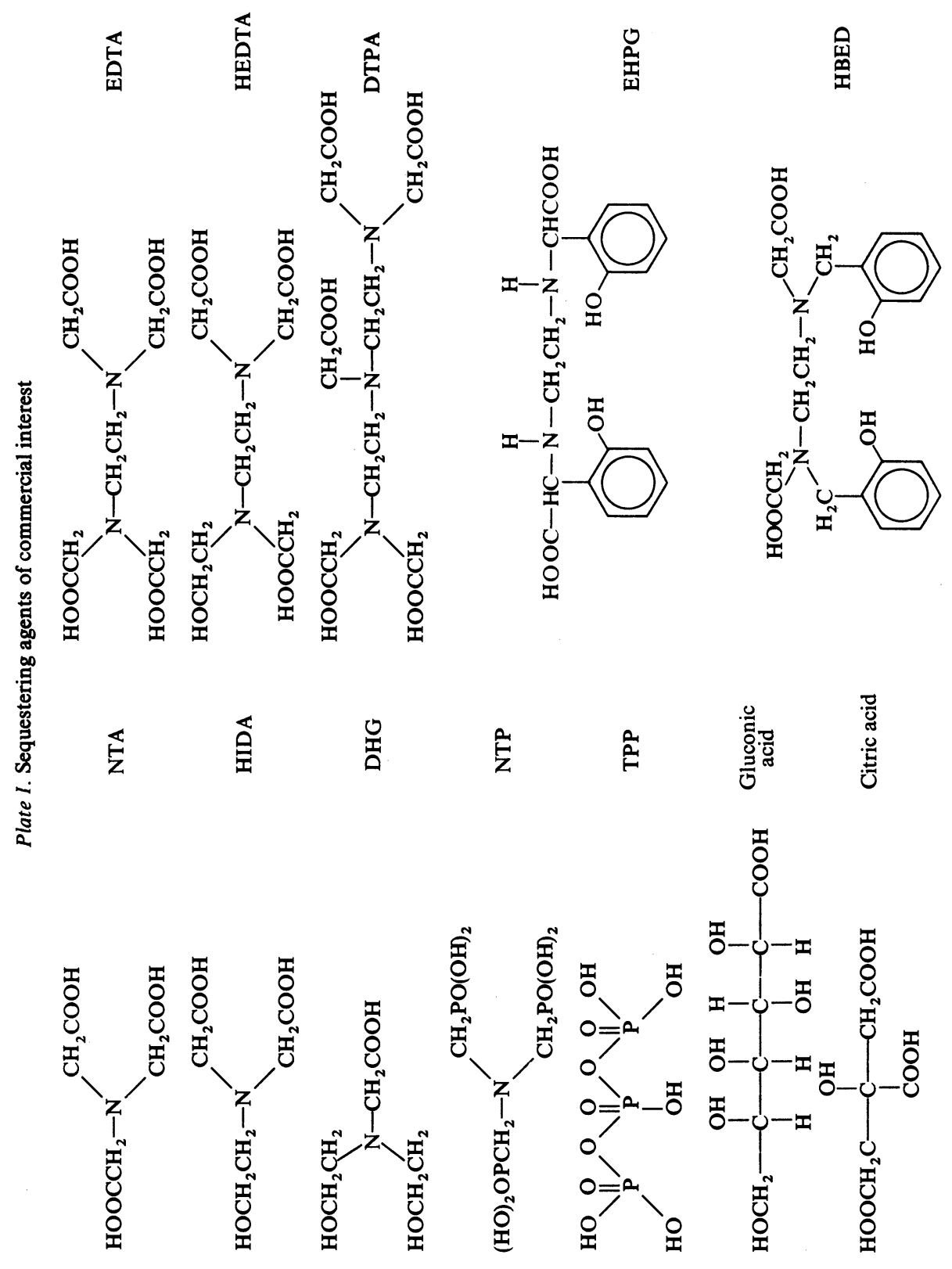


amine, not shown) have increasingly higher ranges of solution stabilities of their Fe(III) complexes, the last not being effective below pH 13 but quite useful as a sequestering agent in aqueous caustic soda solution and even in solid sodium hydroxide.

The two hydroxy acids shown are representative of a class of hydroxy acids that have variable affinity for a wide variety of metal ions, depending largely on the relative number of hydroxyl groups. Citric acid is most effective on metal ions that react strongly enough with it to displace the proton from the hydroxyl group. Similarly, with gluconic acid, effective complexation occurs with metal ions (e.g. $\mathrm{Fe}^{3+}$ ) over more or less wide $\mathrm{pH}$ ranges in which the metal ion can displace proton(s) from one or more of the aliphatic hydroxyl groups. In many cases this reaction, which starts with the alpha hydroxyl, proceeds progressively with the displacement of a larger number of protons as the $\mathrm{pH}$ is increased further. Alkaline earth metal ions are very poorly complexed by this ligand except at $\mathrm{pH} 13$ and above, under which conditions the alpha hydroxy proton is dissociated in the presence of calcium(II) and magnesium(II) ions, with the formation of stable soluble complexes.

The tripolyphosphate (TPP) anion is a much more effective general complexing agent for metal ions than is its lower analogue DP (pyrophosphate or diphosphate) and hence has displaced pyrophosphate for many sequesterant applications.

The phosphonic acid analogues of NTA and EDTA, NTP and EDTP, respectively, carry a much higher negative charge in the fully dissociated form than do the parent compounds, and accordingly are more effective for sequestering metal ions of high ionic charge.

In Plate $I$ are listed two EDTA analogues, EHPG and HBED, which have $o$-hydroxyphenyl groups substituted at carbon atoms adjacent to the amino nitrogens. These provide an interesting basic chelating structure indicated below, which seems to be very specific for the Fe(III) ion:

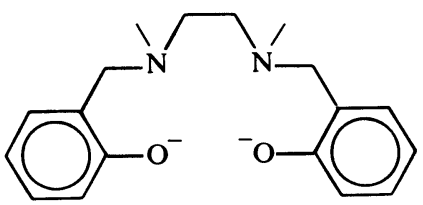

While these ligands have two additional carboxylate groups, those of EHPG are not favourably oriented for strong coordination of an $\mathrm{Fe}^{3+}$ ion which is simultaneously bound to the amino and phenolate groups. Consequently, the stability of the Fe(III) chelate of HBED is much greater (a factor of more than $10^{5}$ ) than that of EHPG. Both ferric chelates are sufficiently stable to resist competition by hydroxyl ion in strongly alkaline solution.

All of the ligands in Plate I, except for HBED, are available commercially and are employed as sequestering agents. The quantities of these substances now being used vary considerably, depending on the nature of the applications and the prices at which they are available. There seems to be no reason to expect that EDTP should be much more expensive to 
produce than is EDTA, and the cost of HBED should be comparable to that of EHPG, so that eventual adoption of these two substances is expected. The varied nature of the functional groups of the ligands listed in Plate I suggests many new combinations of these groups to provide a still greater variety of chelating agents. There seems to be no reason to expect that such sequestering agents will not become readily available as the need arises.

\section{Formation constants}

The stability constants of the $1: 1$ metal chelates of a representative group of sequesterant type chelating ligands, are presented in Table 9. The constants listed for NTA, HIDA, EDTA and HEDTA are selected or 'critical constants' taken from a new compilation by Martell and Smith ${ }^{27}$. On the other extreme only incomplete data, frequently from a single investigation, are available for NTP, TPP and EDTP, as well as for EHPG and HBED. Since stability constants are in themselves practically meaningless without information on the dissociation constants of the ligands, the corresponding $\mathrm{pKs}$ (logarithms of proton association constants) of the ligands in Table 9 must also be considered. Criteria for the selection process are described elsewhere 27 .

As can be seen from the data in Table 9, the broad-spectrum, low-selectivity ligands EDTA and NTA complex a wide variety of metal ions at a relatively high level, while the EDTA chelates are several orders of magnitude more stable than the corresponding NTA chelates. Extension of the basic aminopolycarboxylic acid structure of NTA and EDTA to DTPA results in a further large increase in stability, except for metal ions that have low coordination numbers.

It is interesting to note that the substitution of hydroxyethyl groups for acetic acid groups in NTA and EDTA generally decreases the stability constants of all metal complexes, which is what would be expected if the hydroxyethyl group does not lose a proton and remains a very weakly coordinating ligand. For the chelates of HIDA and HEDTA in Table 9, there is no evidence for proton dissociation from the hydroxyethyl groups, thus explaining the stability constants cited. Remaining unexplained, however, is the fact that iron(III) chelates of these ligands are more hydrolytically stable than those of the parent compounds, NTA and EDTA, even though the latter have higher stability constants. A tentative explanation, offered here for the first time, is that the hydroxyethyl group may stabilize the hydroxo forms of the iron(III) chelates through hydrogen bonding interaction, thus stabilizing them against further hydrolysis or disproportionation to insoluble iron(III) hydroxide and the normal iron(III) chelate. On the other hand the unusually high stabilities of the iron(III) chelates of TEA, and DHG at very high pH can only be accounted for by invoking hydroxyethyl group dissociation to form very strongly-coordinating negatively-charged alkoxy groups.

The stability constants listed for TPP show fairly strong binding of the alkaline earths, but relatively weak affinities for transition and main group metal ions. Because of its lower basicity, it is a more effective sequestrant for alkaline earth ions at low pH than is NTA, but has much lower affinity than does NTA for transition metal ions. 
ARTHUR E. MARTELL

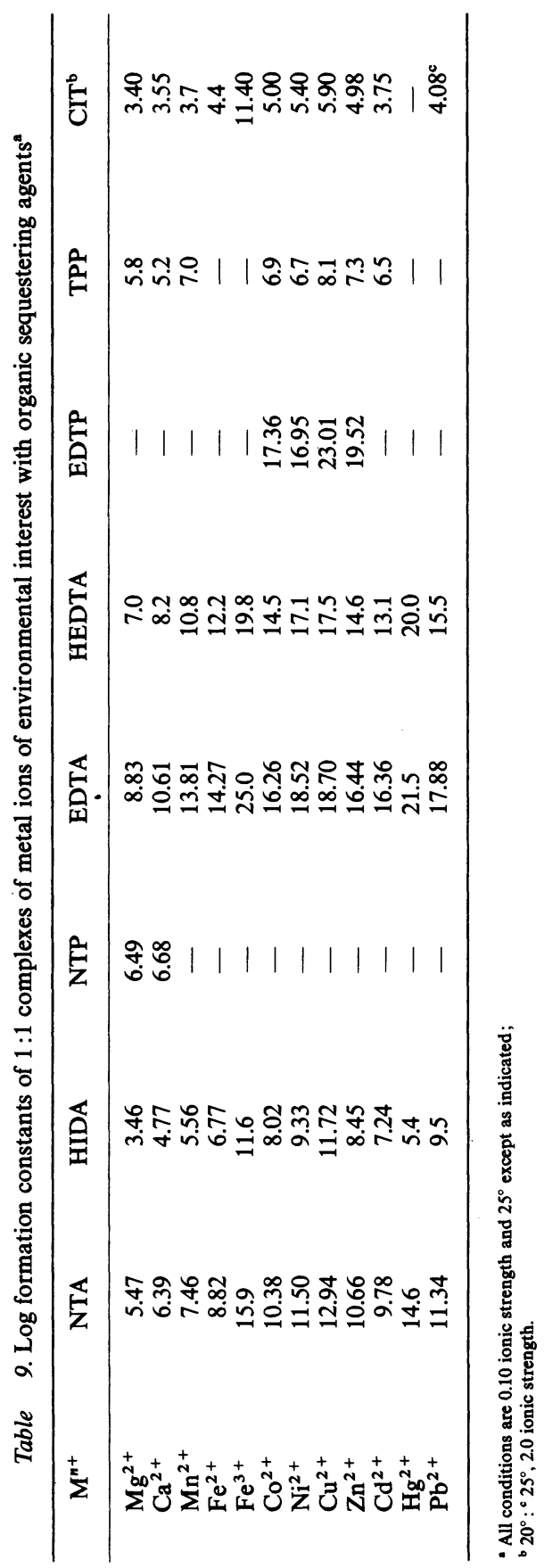


It is emphasized that, except in very high $\mathrm{pH}$ solutions, competition with protons must be considered in comparing metal ion affinities of various ligands. Thus the very high stabilities of transition metal complexes of EDTP listed in Table 9 are counteracted by the very high affinity of the octanegative ligand for protons. Accordingly, below pH 10-12, the EDTA chelates would generally turn out to be more stable than those of EDTP. In the case of EDTP, strong proton competition is counteracted somewhat by the fact that the protonated forms of the ligands also have high affinities for metal ions.

Similar considerations apply to other stability comparisons that appear in Table 9. Thus there is a $\mathrm{pH}$ range in the acid region where the citrate chelates of alkaline earth ions are more stable than those of NTA and even of EDTA. Similarly, there are pH ranges in which metal complexes of triphosphate are more stable than those of more basic ligands having higher metal ion formation constants.

\section{Commercial uses of sequestering agents}

As indicated above the utility of a ligand as a sequestering agent for a wide variety of purposes correlates well with high affinity for a large number of different metal ions. Thus extensive applications are incompatible with high selectivity and differentiation between metal ions. The ligands currently produced and used in the largest amounts, TPP, EDTA, and NTA have the required metal ion affinities and corresponding low selectivities. Each of these ligands will be discussed individually below.

The amounts of these sequestering agents now produced are considerable. Pentasodium tripolyphosphate has reached the level of $2.5 \times 10^{9}$ pounds per year in the USA, and about a total of $4 \times 10^{9}$ pounds for the world. About 200 million pounds of organic sequestering agents per year consist of about 75 million pounds of EDTA, 60 million pounds of NTA, with the remainder consisting of the other sequestering agents indicated in Plate I.

\section{EDTA}

Excluding applications as detergent builders, EDTA is used more extensively and for a wider variety of applications, than any other sequestering agent. The most important and most interesting of these applications are listed in Table 10. Of the large scale uses, the three most important in terms of quantities of EDTA involved are as a general and specialty cleaning agent, textile applications and in the form of its metal chelates in liquid fertilizers. Paper and rubber use smaller but significant amounts. The minor uses listed in Table 10 are minor only with respect to the quantities involved, since EDTA is in several cases very important for the particular application or process cited.

Perhaps the largest use of EDTA at present is as a cleaning agent. It may be employed to remove iron and lime scale from industrial equipment, both metallic and non-metallic. A very critical and important use is the application of EDTA in conjunction with an ammoniacal solution for cleaning high pressure industrial boilers. Highly undesirable redeposition of traces of copper on the iron prevented development of this application for some time but this has now been eliminated by aeration near the end 
Table 10. Commercial applications of EDTA

\begin{tabular}{|c|c|}
\hline \multicolumn{2}{|c|}{ Major applications } \\
\hline Cleaning agent & Plant nutrition \\
\hline $\begin{array}{l}\text { Industrial } \\
\text { equipment, boilers, etc. }\end{array}$ & $\begin{array}{l}\mathrm{Zn} \text { (III) complex } \\
\text { corn, cottun, soy beans }\end{array}$ \\
\hline $\begin{array}{l}\text { Specialty cleaners } \\
\text { bathroom, germicidal preparations }\end{array}$ & $\begin{array}{l}\mathrm{Fe}(\mathrm{III}) \text { complex } \\
\text { to combat chlorosis in citrus trees, } \\
\text { commercial agriculture, home gardens }\end{array}$ \\
\hline $\begin{array}{l}\text { Textiles } \\
\text { Peroxide stabilizer } \\
\quad \text { (DTPA somewhat better) }\end{array}$ & $\begin{array}{l}\mathrm{Mn}(\mathrm{II}), \mathrm{Mg}(\mathrm{II}) \text { complexes } \\
\text { (smaller amounts) }\end{array}$ \\
\hline $\begin{array}{l}\text { Removal of contaminants prior to dyeing } \\
\text { process }\end{array}$ & $\begin{array}{l}\mathrm{Cu}(\mathrm{II}) \text { complex } \\
\text { used in traces }\end{array}$ \\
\hline Levelling agent for regular and metalized dyes & $\begin{array}{l}\text { Cold rubber polymerization } \\
\text { Carrier for } \mathrm{Fe}(\mathrm{III}) / \mathrm{Fe}(\mathrm{II}) \text { redox system }\end{array}$ \\
\hline $\begin{array}{l}\text { Pulp and paper manufacture } \\
\text { Removal of iron in processing }\end{array}$ & \\
\hline $\begin{array}{l}\text { Food and soft drink additive } \\
\text { Purification of pharmaceuticals and } \\
\text { chemical reagents } \\
\text { Processing of colour film } \\
\text { Analytical reagent }\end{array}$ & $\begin{array}{l}\text { Lead poisoning }\left(\mathrm{Na}_{2} \mathrm{Ca}-\mathrm{EDTA}\right) \\
\text { Stabilization of soaps, oils } \\
\text { Antidote for cyanide poisoning [Co(II)-EDTA] } \\
\text { Specialty cleaners } \\
\text { Perborate stabilization }\end{array}$ \\
\hline
\end{tabular}

of the cleaning process to keep the copper in solution as the copper(II)-EDTA chelate. The tetrasodium salt of EDTA may be added to specialty cleaning agents for the removal of iron strains and insoluble metal precipitates from the surface of metals, ceramics or glass. Since its sequestering action on iron does not extend above $\mathrm{pH} \mathrm{8,} \mathrm{EDTA} \mathrm{cannot} \mathrm{be} \mathrm{employed} \mathrm{generally} \mathrm{for}$ alkaline scale removal, with the exception of its use in conjunction with excess ammonia and amines as noted above.

The application that is perhaps second in the quantity of EDTA employed is the production of chelates of essential trace metals for plant nutrition. This is a relatively new development arising from the increased importance of liquid fertilizers. The large scale application of major agricultural fertilizers in solution form has made feasible the simultaneous application of minor and trace elements at the same time. Thus water-soluble complexes of iron, zinc, manganese, magnesium and copper are frequently added along with compounds of nitrogen, phosphorus and potassium. For such applications EDTA has a number of advantages, such as the solubility of its metal complexes, and their high stabilities, which prevent precipitation due to hydrolysis. A large amount of EDTA is used as the zinc(II) complex to correct deficiency of this metal in corn, soy bean and cotton crops. This is currently the major use of EDTA for minor element nutrition of plants, and exceeds the use of the iron(III)-EDTA chelate by an order of magnitude. The latter compound was the first metal chelate to be employed in plant nutrition; it is currently in widespread use for both commercial agriculture and home gardens for combatting iron chlorosis. In addition to its routine use in commercial and retail liquid fertilizers, it is frequently added to solid 
inorganic fertilizers, organic fertilizer preparations and prepared potting soils. The amounts of the manganese-EDTA chelate employed are considerably less than the zinc complex; the magnesium complex is also used in small quantities since magnesium deficiency is relatively uncommon. The copper(II)-EDTA complex is employed only in traces.

The use of EDTA in textiles is historically the first major use of EDTA, since it was first marketed as Trilon B by IG Farbenindustrie, and is still a major use with about 20 per cent of the total market. Its major application is the removal of trace metal impurities prior to processing and dyeing of natural and synthetic fibres. Such impurities are derived from natural sources in the case of cotton and wool, and additional metal contaminants are usually added to cotton by harvesting and processing machinery, and to wool and synthetic fibres by the machinery used in processing or manufacture. Since most dyes (including 'metalized' dyes as well as purely organic dyes) combine with metals to produce different-coloured complexes, the metal impurities must be removed first by a sequestering agent (levelling agent) to produce uniform colour. EDTA and other chelating agents are also used to stabilize peroxide (by trace metal complexation) used in the bleaching of fabrics prior to dyeing.

EDTA is used in considerable amounts to remove metal impurities in the manufacture and processing of pulp and paper. These harmful impurities, which consist mainly of iron but may include other trace transition metals create 'hot spots' on the finished product which catalyse oxidative degradation of the cellulose on subsequent exposure to oxygen and/or light. This oxidation process results in the formation of weak spots and ultimately the physical deterioration of the paper.

The use of EDTA in formulations for the polymerization process that produces 'cold rubber' is still an important application. In this process, EDTA is used to complex the $\mathrm{Fe}^{3+} / \mathrm{Fe}^{2+}$ system in the aqueous phase of an emulsion system to prevent precipitation of ferric hydroxide. The ferric chelate is reduced by a water-soluble, oil-insoluble reducing agent such as glucose and the ferrous ion then is extracted into the organic phase where it interacts with organic peroxide to form $\mathrm{Fe}^{3+}$ and free radical polymerization initiator.

The minor uses of EDTA listed in Table 10 include some important applications, notably medicinal and drug preparation. The calcium chelate is injected intravenously to treat patients suffering from acute lead poisoning. In this case the calcium chelate is employed to prevent lowering of the calcium level of the blood, which would occur if the simple sodium salt were employed. Exchange of lead for calcium produces the 1:1 leadEDTA chelate which is rapidly eliminated in solution form in the urine. A new medicinal application that may become quite important involves the cobalt(II)-EDTA chelate as an antidote for cyanide poisoning. Although the mechanism of the reaction is unknown, a cobalt-cyanide-EDTA mixed ligand complex may be formed, possibly stabilized by oxidation to the cobalt(III) state.

Perhaps the largest scale 'minor' use listed in Table 10 is the addition of EDTA to perborate-type detergents to slow down spontaneous decomposition of the perborate by complex formation with transition metal ions 
that catalyse such processes. This type of application is important in Europe, where borate-containing detergents are commonly used.

One of the important minor applications of EDTA is in the sequestration of trace metals in the preparation of foods. In some cases EDTA is merely used to remove trace metals from foodstuffs, as in the extraction of catalytically active transition metals in oils and fats, especially those formed by catalytic hydrogenation of unsaturated vegetable oils. EDTA is frequently added to soaps to remove trace metals that catalyse oxidation by atmospheric oxygen, resulting in a condition known as oxidative rancidity. Also, food products such as shellfish are frequently treated with EDTA prior to freezing for the market in order to remove the trace transition metals that are naturally present or sometimes are derived from contact with metal equipment. Removal of such impurities (copper ion in the case of shellfish) prevents oxidative discoloration and loss of flavour resulting from metalloenzyme action. In the preparation of pure chemicals and drugs, trace metals also frequently cause discoloration and catalytic oxidative degradation. EDTA is frequently employed to complex and thus inactivate such metal impurities. One common method is to add EDTA to the final solution employed in fractional recrystallization, thus retaining the metal impurities in the mother liquor.

Another interesting application of EDTA is to add the iron(III)-EDTA complex to the solutions employed in the processing of colour film. In this case the iron(III) complex of EDTA replaces potassium ferrocyanide and functions by oxidizing and complexing the silver metal to form a soluble complex, which is then extracted.

A widespread use of EDTA familiar to most inorganic and analytical chemists is as a titrimetric reagent for analysing and standardizing metal ion solutions. For this purpose the disodium salt of EDTA is available in such high purity that it may be weighed out directly as a primary standard for preparing standard solutions of acids and of metal salts, as described by Schwarzenbach ${ }^{28}$.

\section{Sodium tripolyphosphate (STPP)}

Tripolyphosphate, as its pentasodium salt, is by far the most extensively used sequestering agent in the world today. In the USA alone, nearly $2.5 \times 10^{9}$ pounds are produced each year. Although the most extensive single use (Table 11) is as a builder for laundry detergents, other important applications include: builder for dishwashing detergents, dispersing agent for oil drilling muds and for the manufacture of cement, and the curing of meats (such as ham).

The use of tripolyphosphate as a builder for detergents has several advantages: it is inexpensive, forms soluble complexes, does not require high $\mathrm{pH}$ for complex formation and is fully biodegraded by simple hydrolysis, thus not raising the BOD of lakes and streams. The relatively low formation constants of its metal complexes are countered by its low basicity, by its use in considerable excess and by a dispersal effect called 'threshold action'. The mechanism of this property seems to be the ability to maintain hard water metal precipitates in a well-dispersed colloidal form until they are washed away. 


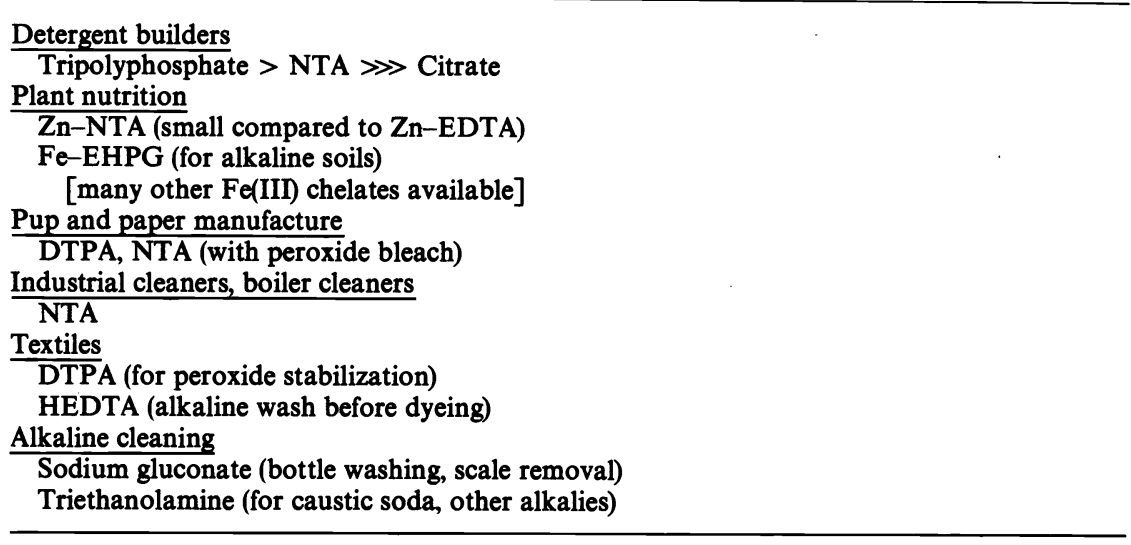

Manufacturers of tripolyphosphate claim that this material is unfairly maligned as the cause of eutrophication of lakes and streams, and point to other essential elements, mainly nitrogen, that also cause rapid growth of algae. It is also pointed out that there are many other sources of phosphates, such as agricultural fertilizer and end products of human and animal metabolism that probably release even more phosphate to the environment, and which are amenable to at least partial control. Proponents of phosphates in detergents also call for complete removal of phosphates by precipitation in the course of secondary waste treatment in sewage plants. Opponents of phosphates in detergents consist mainly of environmentalists, manufacturers of phosphate substitutes, such as NTA, and some detergent manufacturers who are convinced that NTA is the answer. Removal of the phosphate from sewage apparently has been shown to be beneficial in some areas (e.g. Lake of Zürich). However, alteration of sewage plants to provide secondary or tertiary phosphate removal will be very expensive and will require decades to accomplish. Even if this should be done, the replacement of detergent phosphates by suitable substituents may still be needed to reduce the load on the sewage processing facilities. Also, while the argument that other elements such as nitrogen also stimulate the growth of algae, it appears that phosphate is the only essential material whose release to the environment is capable of control. Nitrogen is produced from many sources and by far the largest proportion is carried to earth from the atmosphere by natural rainfall.

In this connection it has recently been reported by Schindler ${ }^{29}$ that rapid abatement of eutrophication may be expected from phosphorus control alone. Thus, as indicated in Figure 4, when two basins of a lake were fertilized with equal amounts of nitrate and sucrose and, in addition phosphorus was added to one of the basins, the phosphate-enriched basin became highly eutrophic while the basin receiving only nitrogen and carbon remained at pre-fertilization conditions. 


\section{ARTHUR E. MARTELL}

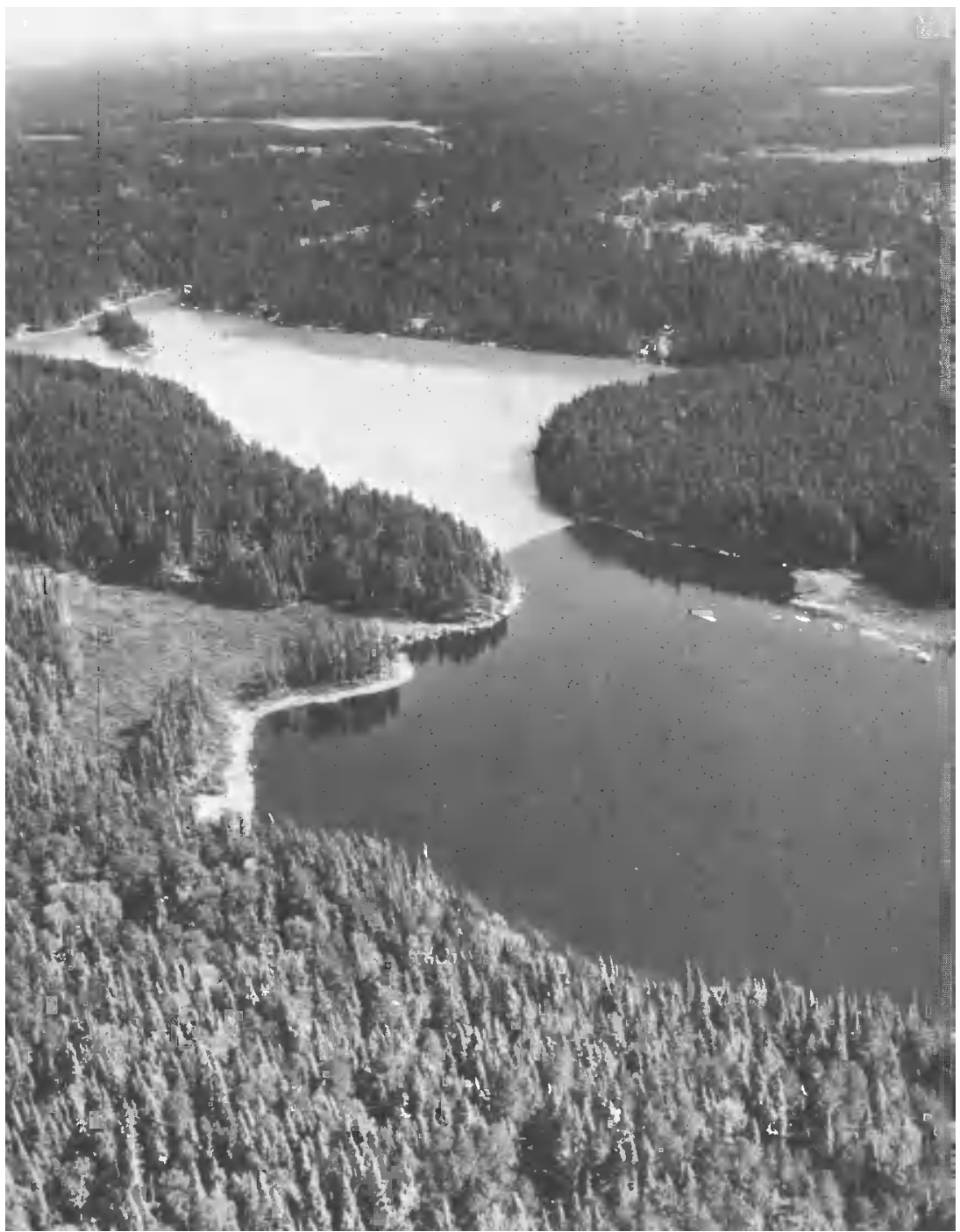

Figure 4. Comparison of two basins of a lake in northwestern Ontario with respect to phosphateinduced eutrophication. The far basin fertilized with phosphorus, carbon and nitrogen was covered with an algae bloom within two months. The near basin received carbon and nitrogen, but no phosphorus. (Reproduced through the courtesy of Science, and the author, D. W.

Schindler; copyright 1974 by the American Association for the Advancement of Science.)

\section{NTA}

Some of the applications of NTA are listed in Table 11, along with the uses of other sequesterng agents. In spite of the temporary withholding of NTA from detergents in the USA, its most extensive use is as a detergent builder. In addition to increasing use of NTA in detergents in Canada and Sweden, it is also used for internal applications by industry as a constituent 
of special cleaners and detergents. Second in order of the quantity employed is the use of NTA for boiker cleaning. In this application it has an advantage over EDTA in being more thermally (hydrolytically) stable in aqueous solution, thus improving its adaptability for the cleaning of high-temperature, high pressure boilers.

Because of the sharp decrease in the cost of production of NTA that occurred in 1969-70, NTA has begun to creep into applications previously dominated by EDTA. Thus the zinc(II)-NTA chelate is beginning to be employed to some extent for plant nutrition in commercial liquid fertilizers. Also, NTA is used to remove metal impurities from paper pulp and from textiles. An interesting development is the increasing use of NTA in Europe to replace EDTA for the stabilization of perborates in detergents. It is only slightly less effective than EDTA, is less expensive, and is currently receiving favourable attention because it is more rapidly biodegradable than is EDTA.

The developments that have occurred in the USA with respect to the use of NTA in detergents are outlined in the next section.

\section{The NTA story}

When large amounts of chemicals are released to the environment, questions immediately arise concerning their environmental impact and possible hazards to human health. When the substance involved is a chelating agent known to have considerable affinity for metal ions and is so new that there are insufficient toxicity data, the issues become a matter of public debate and government regulation. Under such circumstances unsubstantiated claims and counter claims may come to the attention of the public, with resultant confusion among both the public and government officials. The policies developed and carried out under such circumstances are frequently irrational and misguided. Such mistakes are very serious and farreaching because of the amount of material involved, the rather extensive economic impact and the psychological and political problems attendant on admitting and correcting such extensive errors. As an example of what can happen, the chronological events involved in the use of NTA in detergents in the USA is outlined below (Table 12).

Because of the possible impact of NTA on the environment that may result from its widespread use in detergents and the problems of government and public acceptance as outlined in Table 12, it would seem that a somewhat more detailed analysis of available data would be in order. The following is a discussion of the most recent data available.

\section{Environmental concentrations of NTA}

Answers to major questions about the safety of NTA and its environmental effects must be based on realistic estimates of the NTA levels that might occur in surface and ground waters serving as domestic water supplies. Tests of this nature have been carried out in the USA and Canada under conditions of widespread use of NTA in detergents. Cited here is a continuing survey carried out on tap water in thirteen Canadian communities where NTA has been used extensively in detergents (NTA represents about six per cent of the total weight of all laundry products employed). The results 
Table 12. Developments involving the use of NTA in detergents in the USA

$1955-65$

$1965-70$

1969-70

May 1970

June-December 1970

September-December 1970

18 December 1970

January-

September 1971

January 1971present

16 September 1971

February 1972

12 April 1972

5 May 1972

May-August 1972

23 May 1972

September-

October 1972

1 January 1973

July 1973

1972-present

1973-present

1975
Low cost of sodium tripolyphosphate leads to its widespread adoption as a major ingredient in detergents.

Concern increases about environmental effects of phosphates, especially the eutrophication of lakes and streams

Decrease in cost of manufacture of NTA renders it commercially available to replace tripolyphosphate as a detergent builder.

Water Quality Agency of the Department of the Interior demands an immediate cut in the phosphate content of all detergents.

The trisodium salt of NTA is introduced on a large scale into detergents.

Questions raised about safety of NTA and unpublished EPA* report concludes that it increases teratogenicity caused by mercury and cadmium.

Surgeon General of HEW $\dagger$ demands and obtains 'voluntary' withdrawal of NTA from detergents by industry.

Government data on which NTA ban was partially based are found to be erroneous; industrial pressure develops for reinstatement of NTA.

Some manufacturers market detergents containing highly alkaline materials (e.g. sodium carbonate, sodium silicate).

The Surgeon General of HEW and the Director of EPA issue joint Statement warning about alkaline detergents and suggest return to phosphates.

An 8-member panel of scientists (Assistant Secretary's Ad Hoc Group on NTA) is appointed by HEW to examine available evidence on hazards of NTA to human health.

Report of Ad Hoc Group on NTA concludes that tumorigenic and genetic effects are uncertain because conclusive studies had not been carried out.

HEW announces decision to continue 'voluntary' ban on NTA until adequate tests have been completed.

Report of HEW committee criticised by industry and protocol requested for determining carcinogenic and genetic effects of NTA.

Environment Canada announces that detergent manufacturers may choose their own safe substitutes for phosphates (including NTA)

HEW Assistant Secretary's Ad Hoc Committee on NTA recovened and protocol set up. Protocol is criticised by industry as too elaborate and expensive.

Canadian Government requires reduction of phosphate in all detergents to a maximum of five per cent based on $\mathrm{P}_{2} \mathrm{O}_{5}$.

Meeting takes place at HEW to brief representatives of industry on tumorigenic studies under way.

Recent studies on mutagenicity of NaCaNTA (the form found in the environment) indicate the complex to be harmless. Massive doses of $\mathrm{Na}_{3}$ NTA produce some renal carcinomas in mice according to one report, but other reports show no effects. Further carcinogenic studies, especially with $\mathrm{NaCaNTA}$, are needed.

Canadian use of NTA in detergents increases. No harmful effects reported; in practice NTA highly biodegradable.

Erroneous announcement in Chemical and Engineering News (18 August, page 7) that NIH has confirmed NTA as a carcinogen. Present situation confused; low phosphate detergents common; some highly alkaline phosphate-free detergents still in use. 
in Table 13 show that the levels of NTA in drinking water are in the low parts per $10^{9}$ range. Similar results have been obtained in other surveys.

In a number of studies ${ }^{30}$, it has been found that the reductions of the NTA content of sewage occurring in secondary treatment ranges between 60 and $99^{+}$per cent, thus resulting in effluents of a few parts per million. The degree

Table 13. Canadian drinking water survey (Ontario)- $\mathrm{Na}_{3} \mathrm{NTA}$ analysis (parts per $10^{9}$ )

\begin{tabular}{lccc}
\hline \multicolumn{1}{c}{ Community } & December 1971 & July 1972 & January 1973 \\
\hline Brantford & 38 & 6 & 8 \\
Chatham & 55 & $<1$ & 11 \\
Frankford & $<1$ & $<1$ & 4 \\
Guelph & $<1$ & 1 & $<1$ \\
Hawkesbury & 5 & 3 & 3 \\
Kemptville & $<1$ & 3 & 1 \\
Peterborough & $<1$ & $<1$ & $<1$ \\
Smithfalls & $<1$ & 1 & 3 \\
Stouffville & $<1$ & $<1$ & $<1$ \\
Stratford & $<1$ & $<1$ & $<1$ \\
Uxbridge & $<1$ & $<1$ & 3 \\
Welland & $<1$ & 1 & 5 \\
Whitby & 4 & & \\
\hline
\end{tabular}

of dilution that occurs in going from sewage effluent to receiving waters may vary widely from community to community, from 10 -fold to over 1000 -fold. Such dilutions and further biodegradation result in the low levels in receiving waters as indicated in the Canadian study. If the concentrations of NTA in detergents were increased further to 25 per cent, as seems likely, it is estimated ${ }^{30}$ that the levels in tap water would be no greater than 25 parts per $10^{9}$.

\section{Degradation products}

The route of environmental degradation of NTA is not known, although various possible routes, indicated in Plate II, have been postulated by Epstein $^{31}$. It has been found that over 90 per cent of NTA is microbially converted to inorganic constituents ${ }^{32}$. Attempts to isolate degradation intermediates have been entirely unsuccessful. There is no evidence for the accumulation of any of the intermediates indicated in Plate II, except for $N$-oxalyliminodiacetic acid, which was found in one experiment only ${ }^{33}$, and which completely disappeared on completion of NTA degradation.

Because of the concern raised by Epstein ${ }^{31}$ that iminodiacetic acid (IMDA) would be an intermediate in NTA degradation and that it might form a potentially carcinogenic $N$-nitroso derivative, special effort was expended in the detection of IMDA and $N$-nitroso IMDA, with completely negative results. Iminodiacetic acid and sarcosine were found to degrade more rapidly than NTA in an NTA-acclimatized bacterial culture, consistent with the postulation that they are intermediate in NTA biodegradation ${ }^{34,35}$. The slow degradation of $N$-methyliminodiacetic acid in the same bacterial system indicates that it is not an intermediate in NTA degradation. The obvious explanation, therefore, for the lack of isolation of intermediates in 


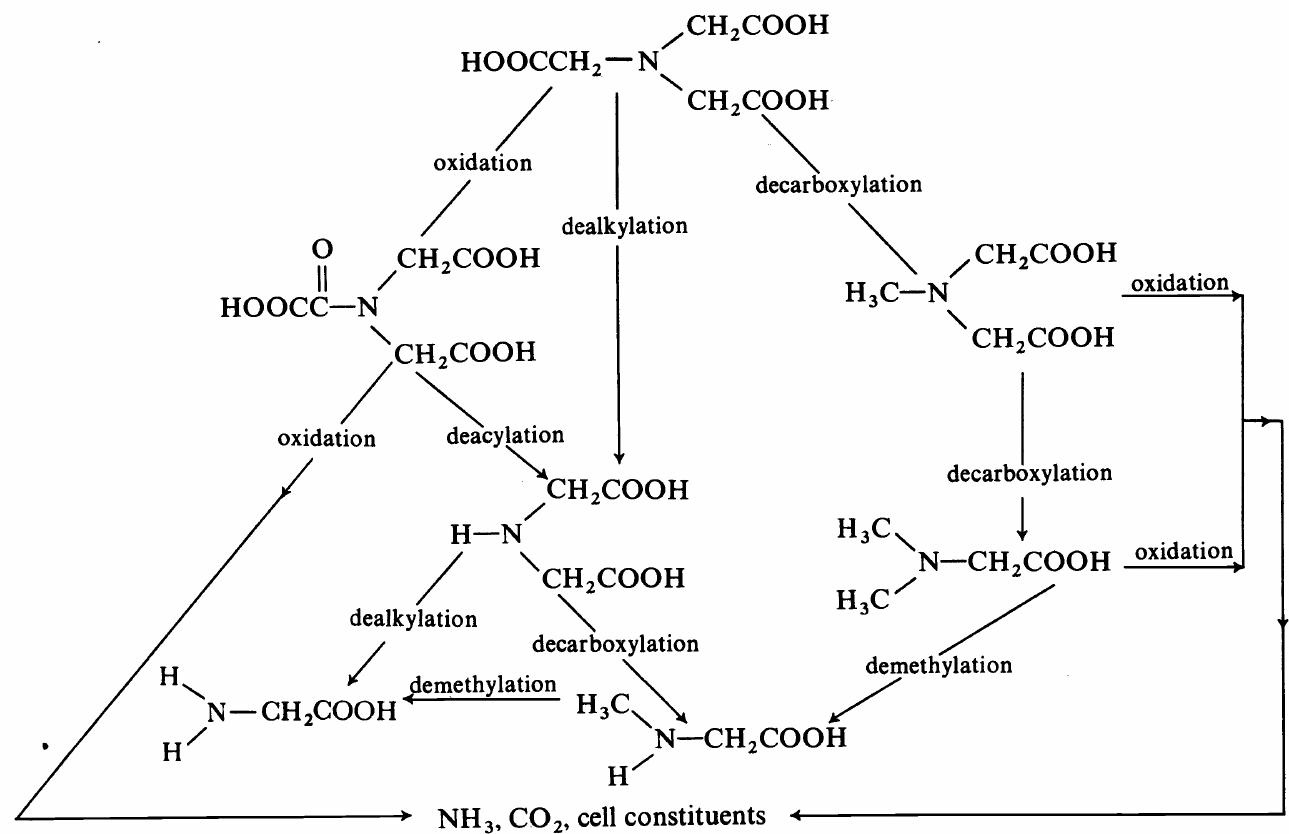

NTA degradation is that the intermediates degrade much more rapidly than does the parent compound, so that their steady-state concentrations are relatively very low. Therefore any fears of side reactions resulting from degradation products of NTA seem to be unfounded.

\section{Effect of NTA on the ecosystem}

There seems to be no reason for concern about the potential toxicity of . NTA in fresh and marine waters. There seem to be no toxic effects on fish and there is a report that NTA lowers copper and zinc toxicity ${ }^{36}$. Similar evidence indicating lowered uptake of toxic metals by fish in the presence of NTA $^{37}$ is presented in Table 14. There seem to be no explanations or mechanisms for these observations. Because of the complexities of the systems involved, interpretations based merely on the formation of metal-NTA complexes seem much too simplistic.

Since NTA has been proposed as a substitute for phosphate in detergents to lower eutrophication in lakes and streams, questions have been raised as to the possible contribution of NTA itself to eutrophication through the supplying of nitrogen compounds as a nutrient. It turns out that the supply of nitrogen in fresh and marine waters by natural processes is so high that the formation of ammonia or nitrate by NTA would have a negligible effect. Conservative estimates of fixed nitrogen entering surface water give $5-10 \times 10^{9} \mathrm{lb}$ per year. If one takes the extreme situation in which all detergents would contain 25 per cent NTA, about $5 \times 10^{6} \mathrm{lb}$ of nitrogen 
Table 14. Effect of sequestering agents on absorption of toxic metals by fish

$\mu \mathrm{g}$ metal/g ash after $48 \mathrm{~h}$ exposure

\begin{tabular}{lrc}
\multicolumn{1}{c}{ Metal ion or complex } & Gut & Whole fish \\
\hline Zn 20 p.p.m. & 15170 & 2994 \\
Zn 20 p.p.m. + EDTA & 8704 & 2598 \\
Zn 20 p.p.m. + NTA & 7313 & 2476 \\
Cd 2 p.p.m. & 1749 & 24 \\
Cd 2 p.p.m. + EDTA & 50 & 0.7 \\
Cd 2 p.p.m. + NTA & 137 & 2 \\
Cu 0.1 p.p.m. & 346 & 40 \\
Cu 0.1 p.p.m. + EDTA & 211 & 71 \\
Cu 0.1 p.p.m. + NTA & 107 & 25 \\
Pb 2 p.p.m. & 1846 & 50 \\
Pb 2 p.p.m. + EDTA & 236 & 1 \\
Pb 2 p.p.m. + NTA & 339 & 1 \\
\hline
\end{tabular}

would be added in the form of ammonia or nitrate. Thus the maximum possible effect of widespread use of NTA would be to add 0.1 per cent to available nitrogen in fresh and marine waters. Accordingly, it is not surprising that field studies have shown no significant effects on algae growth of up to 100 parts per $10^{9}$ of NTA $^{30}$.

Questions have been raised ${ }^{31}$ concerning the effect of NTA on the mobilization of toxic metal ions in lakes and streams and also on the increase in availability of essential trace metals. Model experiments and calculations have clarified some aspects of the problem ${ }^{38}$. When NTA is added at 100 parts per $10^{9}$ to a solution of metal ions at concentrations corresponding to average US public water supplies, but with no trivalent ions present, 98 per cent of the NTA would be complexed by $\mathrm{Cu}^{2+}$, most of the balance would be complexed by $\mathrm{Zn}^{2+}$ and only traces would combine with $\mathrm{Pb}^{2+}$, $\mathrm{Hg}^{2+}, \mathrm{Cd}^{2+}$ and $\mathrm{Mn}^{2+}$. However, in the presence of $\mathrm{Fe}^{3+}, 99.8$ per cent would combine with the ferric ion. Moreover, the addition of ferric hydroxide to such a system results in removal of the NTA as an insoluble complex. Thus in a real system, it is seen that contact with hydrolysed forms of $\mathrm{Fe}^{3+}$ on the soil would remove the NTA rather than solubilize the metal ion.

\section{Human safety}

When the US Surgeon General in December 1970 requested voluntary discontinuance of the use of NTA by the detergent industry, it was estimated that $1.25 \times 10^{9} \mathrm{lb}$ of NTA per year (corresponding to 25 per cent NTA in all detergents) might eventually be released to the environment. On this basis there were estimates that drinking water could contain three to four parts per million. As has been indicated earlier in this paper, drinking water samples have been in the low parts per $10^{9}$ range in the regions where NTA usage has been widespread. These low probable concentrations should provide a safety factor of about 100000 when compared to the doses necessary to produce toxicological damage in test animals.

In addition, the Surgeon General was particularly concerned about the 
results of a preliminary report that indicated that NTA might enhance the teratogenic activity of methylmercury and cadmium ${ }^{39}$. These results were far from conclusive and involved poorly designed experiments to demonstrate the desired comparison of effects with and without NTA. In the absence of NTA, the controls contained added cysteine to keep the toxic metals in solution, thus reducing the experiment to a comparison of NTA and cysteine as ligands for these metal ions. Subsequent investigations ${ }^{30,40}$ of the influence of NTA on teratological effects of cadmium and methylmercury demonstrated the lack of any adverse effects and indicated that NTA had a slight protective effect.

In September 1971, the Surgeon General expressed concern that NTA had not been proved to be non-carcinogenic. In February 1972 an Ad Hoc Committee was appointed by the US Department of Health, Education and Welfare under the Chairmanship of Dr L. A. Woods to examine the data relating to human safety of NTA. Its report ${ }^{41}$ concluded that NTA is not likely to be toxic to man at the concentrations encountered in daily use but expressed reservations with respect to the incompleteness of data on mutagenicity and carcinogenicity.

\section{Other effects of NTA in mammals}

(a) Metabolism-The absorption and metabolism of NTA has been studied in rats, rabbits, dogs, monkeys and $\operatorname{man}^{30}$. While readily absorbed from the gastro-intestinal tract of rats and dogs, it was not absorbed by rabbits and monkeys. In humans preliminary studies have indicated that from five to twelve per cent of the NTA appears in the urine and that the remainder, giving a material balance of 98 per cent, appears in the faeces. Analysis of urinary products shows that the NTA is excreted unchanged and that no metabolic reactions occur in the body.

(b) Effect on metal ion distribution-The early concerns that NTA in the body may rearrange essential trace metals with consequent serious effects on enzyme function have not been borne out by experiment. In a 90-day feeding experiment $\mathrm{t}^{42}$ and a two-year chronic study ${ }^{43}$, an increase in urinary zinc excretion was observed only at extremely high doses (>1500 p.p.m. in drinking water), but not at lower dosages. The zinc concentration in body tissues including bone was also increased somewhat at these doses. No effect on iron metabolism was found. Even with the highest doses used (up to 20000 p.p.m.) there were no detectable weight changes in the animals and no observable effects on blood and urinary biochemical components.

(c) NTA in bone-In the rat and dog experiments mentioned above, approximately two to three per cent of the total dose was retained for more than three days and the majority of this was found in the bone ${ }^{30}$. Over longer periods of exposure the NTA continues to build up somewhat, but not in proportion to the dose. Single doses of $20 \mathrm{mg} / \mathrm{kg}$ resulted in contents from 1 to $3 \mu \mathrm{g} / \mathrm{g}$ of bone. NTA in bone is gradually eliminated, the turnover time being most rapid for freshly absorbed NTA and is quite slow (with half-lives of months or years) for NTA that has resided in the bone for some time. In any case the percentage of NTA is quite small and tests showed no effect on bone strength. Histopathological examination showed no effects on bone structure and mineralization. 
(d) Effect of NTA on enzymes-Simple model systems can show that NTA will compete with certain enzymes for metal ions. Table 15 illustrates simple competition calculations for NTA and carboxypeptidase, for which some equilibrium data are available. It is apparent that, if NTA could freely go to the region in which the enzyme was functioning, there would certainly be serious effects. Similar effects may be deduced for other enzymes activated by labile metal ions. The effect on magnesium levels, for example, should be considerable.

Table 15. NTA versus carboxypeptidase*

\begin{tabular}{lccccc}
\hline & \multicolumn{2}{c}{ Equilibrium constants } & & & \\
$\mathrm{M}^{2+}$ & NTA (log $\left.K_{1}\right)$ & Carboxypeptidase $\dagger$ & $\begin{array}{c}\text { \%NTA } \\
\text { complex }\end{array}$ & $\begin{array}{c}\% \text { Carboxypeptidase } \\
\text { complex }\end{array}$ & $\begin{array}{c}\% \text { Aquo } \\
\text { ion }\end{array}$ \\
\hline $\mathrm{Mn}^{2+}$ & 7.46 & 5.6 & 25 & 18 & 56 \\
$\mathrm{Co}^{2+}$ & 10.38 & 7.0 & 87 & 12 & 1 \\
$\mathrm{Ni}^{2+}$ & 11.51 & 8.2 & 87 & 13 & 0 \\
$\mathrm{Cu}^{2+}$ & 12.94 & 10.6 & 68 & 32 & 0 \\
$\mathrm{Zn}^{2+}$ & 10.66 & 10.5 & 15 & 85 & 0 \\
$\mathrm{Cd}^{2+}$ & 9.78 & 10.8 & 4 & 96 & 0 \\
$\mathrm{Hg}^{2+}$ & 14.6 & 21.0 & 0 & 100 & 0 \\
\hline
\end{tabular}

* For 1:1:1 molar ratio at pH 8.0;

+ Apparent formation constant at $\mathrm{pH} 8.0$

The predictions based on such simple models are not borne out by experiment. In studies carried out by The Proctor and Gamble Company ${ }^{44}$, rats were fed diets with levels up to 20000 p.p.m. of NTA for 90 days. Histochemical examination of frozen sections of succinic dehydrogenase, cytochrome oxidase, alkaline phosphatase, acid phosphatase, DPN diaphorase, TPN diaphorase and carbonic anhydrase revealed no consistent differences from the controls in either quantity, location and/or distribution of any of these enzymes. All organs showed normal enzyme activity.

\section{General toxicity}

Examination of the data described above shows that none of the effects of NTA are harmful or even questionable except at unrealistically very high concentrations which are $10^{5}$ to $10^{6}$ times the concentration that might be encountered in the environment. This is the same general conclusion that was arrived at by the Woods Committee report ${ }^{41}$, since no evidence was found that pointed to any adverse effects of NTA. The remaining questions of carcinogenicity and mutagenicity should now be readily answered by the forthcoming reports of recent studies by the US Department of Health, Education and Welfare.

It is interesting to note that the acute toxicity of NTA is very low and about the same level as the triphosphate which it is proposed to replace in detergents. In dogs the $\mathrm{LD}_{50}$ is about $5 \mathrm{~g} / \mathrm{kg}$. In a 90 -day subacute toxicity test $\mathrm{t}^{42}$, no adverse effects were observed below 20000 p.p.m. in the diet. The conclusion is therefore inescapable that NTA is a relatively very safe compound. 
Recapitulation of the NTA-tripolyphosphate problem

The question now remains as to what will be done about the phosphateNTA problem in detergents, assuming that forthcoming reports on carcinogenic and mutagenic effects will be favourable to NTA. The following points are offered in summary:

Large scale phosphate use should be eliminated, since:

(1) Phosphate is the only controllable constituent that can be removed to eliminate eutrophication;

(2) The reserves of high grade phosphate ores are very limited and are now estimated at 100 years;

(3) Alternatives that have been offered such as removal of phosphate by precipitation in sewage treatment plants are too expensive.

NTA is the logical substitute for the following reasons:

(1) It is not harmful when ingested and has very low acute toxicity;

(2) It is slightly more efficient than phosphate and could be used in detergents at somewhat lower concentrations;

(3) It is the only cheap substitute available (EDTA would be better but is too expensive);

(4) It will not hurt the environment. Small amounts have even been found to be beneficial;

(5) It is rapidly biodegradable, with a half-life from a few hours to a few weeks, depending on conditions;

(6) No side effects due to coordination of metals have been found to occur in the environment.

\section{ACKNOWLEDGEMENT}

The author is indebted to J. J. Singer and C. S. Johnson for information and helpful discussions on the applications of sequestering agents.

\section{REFERENCES}

1 J. M. Wood, Science, 183, 1049 (1974).

${ }^{2} \mathrm{~K}$. Schwarz, in Trace Element Metabolism in Animals, p 25. C. F. Mills, Ed. Livingstone: Edinburgh (1970).

${ }^{3} \mathrm{~K}$. Schwarz, in Nuclear Activation Techniques in the Life Sciences, p 3. IAEA: Vienna (1972).

${ }^{4} \mathrm{~K}$. Schwarz, private communication.

5 J. B. Andelman, in Trace Metals and Metal Organic Interactions in Natural Waters, pp 57-88. P. C. Singer, Ed., Ann Arbor Science Publishers, Inc.: Ann Arbor, Michigan (1973).

${ }^{6}$ H. A. Schroeder, J. Amer. Med. Ass. 195, 125 (1966).

${ }^{7}$ M. D. Crawford, M. J. Gardner and J. N. Morris, The Lancet, i, 827 (1968).

${ }^{8}$ E. F. Winton and L. J. McCabe, J. Amer. Water Works Ass. 62, 26 (1970).

${ }^{9}$ A. W. Voors, Amer. J. Epid. 93, 259 (1971).

${ }^{10}$ L. G. Sillen, Amer. Ass. Advanc. Sci. 67, 549 (1961).

${ }^{11}$ A. Siegel, in Organic Compounds in Aquatic Environments, S. D. Faust and J. V. Hunter, Eds. Marcel Dekker: New York (1971).

12 G. Steelink, J. Chem. Educ. 40, 379 (1963).

${ }^{13}$ P. G. Manning and S. Ramamoorthy, J. Inorg. Nucl. Chem. 35, 1577 (1973).

${ }^{14}$ M. Schnitzer and E. H. Hansen, Soil Sci. 109, 333 (1970).

15 D. Gamble, M. Schnitzer and I. Hoffman, Canad. J. Chem. 48, 3197 (1970).

$16 \mathrm{~J}$. Schubert, in Metal Ions in Biological Systems: Studies of Some Biochemical and Environmental Problems, Vol. 40, S. K. Dhar, Ed. Plenum: New York (1973). 


\section{METAL IONS AND LIGANDS IN THE ENVIRONMENT}

17 J. M. Wood, in Proceedings of the International Conference on Heavy Metals in the Environment, Vanderbilt University (December 1973).

18 J. M. Wood and D. G. Brown, Struct. Bonding, 11, 47 (1972).

19 R. E. De Simone, M. W. Penley, L. Charbonneau, S. Smith, J. M. Wood, H. A. O. Hill, P. Ridsdale and R. J. P. Williams, Biochim. Biophys. Acta, 304, 851 (1973).

20 G. Agnes, H. A. O. Hill, J. M. Pratt, S. C. Ridsdale, F. S. Kennedy, and R. J. P. Williams, Biochim. Biophys. Acta, 252, 207 (1971).

${ }^{21}$ Lead, Committee on Biological Effects of Atmospheric Pollutants, p 13. National Academy of Sciences: Washington, DC (1972).

22 'Symposium on Environmental Lead Contamination', US Public Health Service Publication No. 1440, Superintendent of Documents, US Government Printing Office: Washington, DC (1960).

23 J. Telsinger, Arch. Environ. Health, 23, 280 (1971).

${ }^{24}$ The Pharmacological Basis of Therapeutics, 4th ed., L. S. Goodman and A. Gilman, Eds. Macmillian: New York (1970).

${ }^{25}$ H. L. Hardy, et al., Clin. Pharmacol. Therapeutics, 12, 982 (1971).

${ }^{26} \mathrm{~J}$. McCaull, Environment, 13, 3 (1971).

27 A.E. Martell and R. M. Smith, Critical Stability Constants, Plenum: New York (1974).

${ }^{28}$ G. Schwarzenbach, Complexometric Titrations. Interscience: New York (1957).

${ }^{29}$ D. W. Schindler, Science, 184, 897 (1974).

${ }^{30}$ P. S. Thayer and C. J. Kensler, Critical Reviews in Environmental Control, 3, 375 (1973).

${ }^{31}$ S. S. Epstein, Internat. J. Environ. Studies, 2, 291; 3, 13 (1972).

32 J. E. Thompson and J. R. Duthie, J. Water Pollut. Control Fed. 40, 306 (1968).

${ }^{33}$ Summary report, Monsanto Company (10 September 1970).

${ }^{34}$ D. D. Focht and H. A. Joseph, Canad. J. Microbiol. 17, 1553 (1971).

${ }^{35}$ C. B. Warren and E. J. Malec, Science, 176, 277 (1972).

36 J. G. Sprague, Nature, London, 200, 1345 (1968).

${ }^{37}$ A. Tsuji, Jap. J. Hygiene, 27, 223 (1974).

${ }^{38}$ W. A. Cilley and D. A. Nicholson, Environ. Letters, 2,121 (1971).

${ }^{39}$ N. Chernoff and K. D. Courtney, unpublished progress report, NIEHS, (1 December 1970).

40 IBTC Reports B162 and B327 to Government/Industry Committee (1971).

41 'Assessment of the potential of nitrilotriacetate (NTA) to compromise human health', Assistant Secretary's Ad Hoc Group on NTA, Final Report to the Assistant Secretary for Health and Scientific Affairs, Department HEW (19 April 1972).

42 G. A. Nixon, Toxicol. Appl. Pharmacol. 18, 398 (1970).

${ }^{43}$ G. A. Nixon, E. V. Buehler and R. J. Niewenhuis, Toxicol. Appl. Pharmacol. 21, 244 (1972).

${ }^{44}$ Unpublished report, The Proctor and Gamble Company. 